\title{
The PCMDI Software System: Status and Future Plans Report No. 44
}

\author{
D.N. Williams
}

August 1997

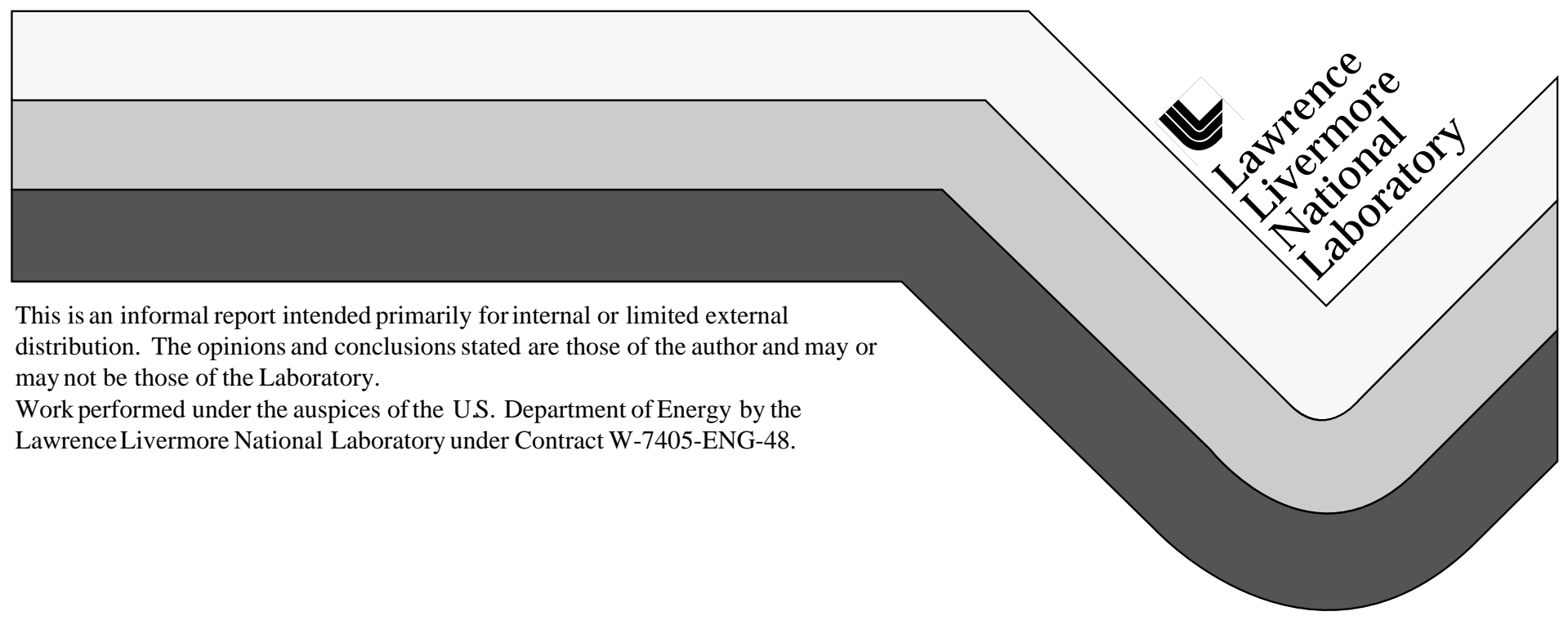




\section{DISCLAIMER}

This document was prepared as an account of work sponsored by an agency of the United States Government. Neither the United States Government nor the University of California nor any of their employees, makes any warranty, express or implied, or assumes any legal liability or responsibility for the accuracy, completeness, or usefulness of any information, apparatus, product, or process disclosed, or represents that its use would not infringe privately owned rights. Reference herein to any specific commercial product, process, or service by trade name, trademark, manufacturer, or otherwise, does not necessarily constitute or imply its endorsement, recommendation, or favoring by the United States Government or the University of California. The views and opinions of authors expressed herein do not necessarily state or reflect those of the United States Government or the University of California, and shall not be used for advertising or product endorsement purposes.

This report has been reproduced directly from the best available copy.

Available to DOE and DOE contractors from the Office of Scientific and Technical Information

P.O. Box 62, Oak Ridge, TN 37831

Prices available from (615) 576-8401, FTS 626-8401

Available to the public from the

National Technical Information Service

U.S. Department of Commerce 5285 Port Royal Rd.,

Springfield, VA 22161 
PCMDI Report No. 44

\title{
The PCMDI Software System: Status and Future Plans
}

\author{
by
}

Dean N. Williams

Program for Climate Model Diagnosis and Intercomparison

Lawrence Livermore National Laboratory, Livermore, CA, USA

August 1997

PROGRAM FOR CLIMATE MODEL DIAGNOSIS AND INTERCOMPARISON UNIVERSITY OF CALIFORNIA, LAWRENCE LIVERMORE NATIONAL LABORATORY LIVERMORE, CALIFORNIA 94550 


\section{Preface}

The Program for Climate Model Diagnosis and Intercomparison (PCMDI) software status and future plans centralizes on software that PCMDI is currently distributing to the global climate community at large or has plans to distribute in the near future. Other secondary software necessary for the distributed software to work will not be included in this document. If anyone wishes to acquire PCMDI software source code, they may do so by filling out the collaboration agreement located on the web (http://www-pcmdi.llnl.gov/software). The collaboration agreement states software ownership (i.e., U.S. Department of Energy) and any selling of this software is prohibited.

The development of PCMDI software would not have been possible without input from the entire PCMDI staff, who have indicated to the author the type of software needed to do their jobs well. Among PCMDI's primary focal points are the intercomparison projects such as the Atmospheric Model Intercomparison Project (AMIP) and the Coupled Model Intercomparison Project (CMIP). Current and future software are designed to accommodate the needs of these intercomparison projects, and it is hoped that the software is flexible enough to assist in other areas of global climate modeling.

It is the desire of the author that anyone interested in PCMDI software provide input to the development of PCMDI software products so that PCMDI can better serve its constituents in the global climate research community. Readers are encouraged to e-mail or write to:

Program for Climate Model Diagnosis and Intercomparison (PCMDI)

Lawrence Livermore National Laboratory

P.O. Box 808, L-264

Livermore, California (USA) 94550

E-mail: williams@pcmdi.llnl.gov

Tel: (510) 422-7626

Fax: (510) 422-7675 
Table of Contents

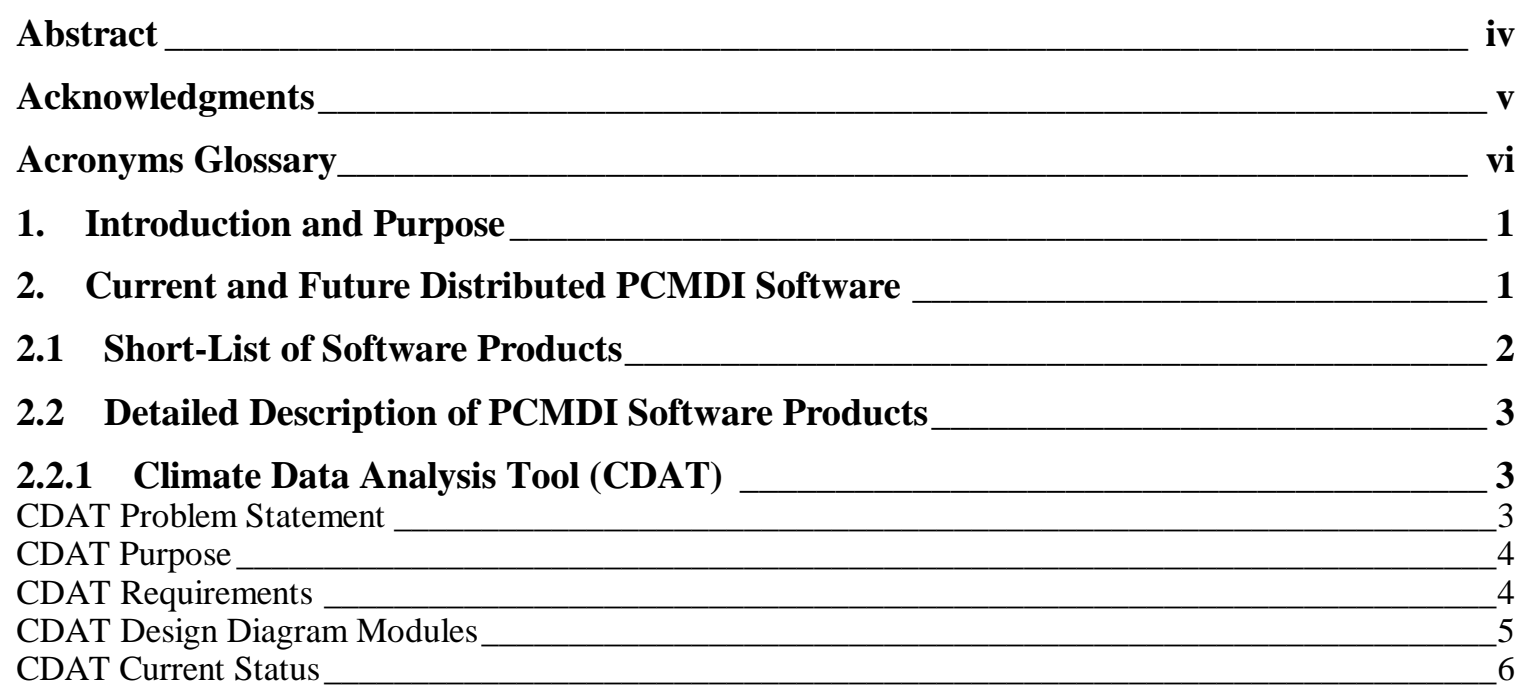

2.2.2 Climate Database Management System (CDMS) _ 6

CDMS Purpose__ 7

CDMS Requirements _ 7

CDMS Design Diagram Modules __ 8

CDMS Current Status___ 9

2.2.3 Climate Data UNIform File (cdunif) Reader ___ 9

Cdunif Problem Statement ___ 9

Cdunif Purpose _ 10

Cdunif Requirements _ 10

Cdunif Design Diagram Modules___ 12

Cdunif Current Status___ 12

2.2.4 Data and Dimension (DDI) ___ 13

DDI Problem Statement ___ 13

DDI Purpose__ 13

DDI Requirements

DDI Design Diagram Modules___ 14

DDI Current Status___ 15

2.2.5 Data Retrieval and Storage (DRS) __ 15

DRS Problem Statement__ 15

DRS Purpose _ 15

DRS Requirements _ 16

DRS Design Diagram Modules __ 16

DRS Current Status _ 17

2.2.6 EzGet 17

EzGet Problem Statement _ 17

EzGet Purpose _ 17

EzGet Requirements__ 17

EzGet Design Diagram Modules ___ 18

EzGet Current Status __ 19

2.2.7 Library of AMIP Data Transmission (LATS) _ 19

LATS Problem Statement _

LATS Purpose _ 19

LATS Requirements__ 19 
LATS Design Diagram Modules

2.2.8 Quality Control Software (QCS)

QCS Problem Statement___ 21

QCS Purpose __ 21

QCS Requirements _ 21

QCS Design Diagram Modules __ 22

QCS Current Status __ 23

2.2.9 Visualization and Computation System (VCS)___ 23

VCS Problem Statement___ 23

VCS Purpose _ 23

VCS Requirements _ 23

VCS Design Diagram Modules __ 25

VCS Current Status __ 26

3. Web Development and Software Documentation ___ 26

4. Multiple Platforms ___ 26

5. Software Collaborations ___ 27

6. Code Repository ___ 27

7. Summary of the PCMDI Software System __ 29 


\begin{abstract}
This report describes the current status and future plans of PCMDI's software products. A complete description of each product is provided, including the product's problem statement, purpose, requirements, design diagram, current status, future development, developers, contributors, and off-site collaborators. While it is noted that each software product can be executed as an independent process, it is important to discern that all products work together in the complete PCMDI Software System: a suite of software tools facilitating for the storage, diagnosis, and visualization of climate data.
\end{abstract}




\section{Acknowledgments}

Input from the entire PCMDI staff was greatly appreciated in preparing this document. Special thanks are due the PCMDI software design and development team which consists of: Jerry Potter, Karl Taylor, Clyde Dease, Charles O'Connor, Susan Marlais and Bob Drach without whom this document would not have been possible. In addition, special thanks to Thomas J. Phillips and W. Lawrence Gates for their editorial assistance and to Anna McCravy for her substantial graphics contribution.

This work was performed under the auspices of the U.S. Department of Energy, Environmental Sciences Division, by the Lawrence Livermore National Laboratory under Contract W-7405-ENG-48. 


\section{Acronyms Glossary}

\begin{tabular}{|c|c|}
\hline ACL & Advanced Computing Laboratory \\
\hline AMIP & Atmospheric Model Intercomparison Project \\
\hline API & Application Programmer's Interface \\
\hline $\mathrm{CCM}$ & Community Climate Module \\
\hline CDAT & Climate Data Analysis Tool \\
\hline CDMS & Climate Database Management System \\
\hline cdunif & Common Data UNIform File Reader \\
\hline CGI & Common Graphics Interface \\
\hline COARDS & Cooperative Ocean/Atmosphere Research Data Service \\
\hline CMIP & Coupled Model Intercomparison Project \\
\hline CVS & Concurrent Version System \\
\hline DDI & Data and Dimension Interface \\
\hline $\mathrm{DEC}$ & Digital Equipment Corporation \\
\hline DRS & Data Retrieval and Storage \\
\hline GUI & Graphical User Interface \\
\hline $\mathrm{HDF}$ & Hierarchical Data Format \\
\hline HP & Hewlett Packard \\
\hline IBM & International Business Machines \\
\hline LANL & Los Alamos National Laboratory \\
\hline LATS & Library of AMIP Data Transmission Standards \\
\hline LLNL & Lawrence Livermore National Laboratory \\
\hline NCAR & National Center for Atmospheric Research \\
\hline NERSC & National Energy Research Supercomputing Center \\
\hline netCDF & network Common Data Form \\
\hline $\mathrm{PC}$ & Personal Computer \\
\hline PCMDI & Program for Climate Model Diagnosis and Intercomparison \\
\hline PMIP & Paleoclimatic Model Intercomparison Project \\
\hline PSQL & PCMDI Structured Query Language \\
\hline PSS & PCMDI Software System \\
\hline PVM & Parallel Virtual Machine \\
\hline QC & Quality Control \\
\hline QCS & Quality Control Software \\
\hline SGI & Silicon Graphics, Inc. \\
\hline SQL & Structured Query Language \\
\hline VCS & Visualization and Computation System \\
\hline VPOP & View POP \\
\hline
\end{tabular}




\section{Introduction and Purpose}

The Program for Climate Model Diagnosis and Intercomparison (PCMDI) was established in 1989 at the Lawrence Livermore National Laboratory (LLNL) with the principal mission to develop improved methods and tools for the diagnosis, validation and intercomparison of global climate models. While playing a leading role in the development of climate diagnostic tools, PCMDI has entered into collaborative agreements with the National Center for Atmospheric Research (NCAR) and the Los Alamos National Laboratory (LANL) for the provision of atmospheric and oceanic diagnostic functions that will be utilized in PCMDI's software products.

This document will focus primarily on the software tools necessary for PCMDI to sustain and meet its short-term and long-term missions. The job assignment(s) envisaged for each PCMDI software development staff member are also described. Here, we will only attempt to project PCMDI software development out for one to two years, with project time lines presented only where these now can be anticipated. As with all projected plans, it is anticipated that, with changes in technology and in the PCMDI staff, future modifications of this document may be needed.

\section{Current and Future Distributed PCMDI Software}

Processing intercomparison model data (i.e., Atmospheric Model Intercomparison Project (AMIP), the Coupled Model Intercomparison Project (CMIP), and the Paleoclimatic Model Intercomparison Project (PMIP) is an important part of PCMDI. All members of the PCMDI software team are directly or indirectly involved in this endeavor and give these projects their primary focus. To fully understand the data processing element of PCMDI see, "Processing and Distributing Intercomparison Data," by Peter Gleckler and Dean N. Williams (in preparation). Reading and writing of intercomparison model data are the software team's highest priority. Thus, it involves the further development of the Common Data UNIform File (cdunif) reader and the Library of AMIP Data Transmission Standards (LATS), both of which are at the core of PCMDI's software.

As an important component of PCMDI's work in the development, testing, validation, and intercomparison of global climate models, PCMDI has developed and distributed a suite of software tools for the storage, diagnosis, and visualization of data. Section 2.1 below presents a short list of the software products that are currently being used at PCMDI and distributed to the climate community at large, or that are under design and development for future release. Section 2.2 describes each PCMDI software product in more detail. Section 4 describes web development and software documentation in detail. Section 5 lists all of the platforms that PCMDI software supports. Section 6 describes the software collaboration agreements with outside organizations. Section 7 describes the needed code repository. Section 9 describes the PCMDI computer system and future upgrades. Finally, section 10 concludes with an overview of PCMDI's primary software goal, the PCMDI Software System.

To further PCMDI's principal mission, development of the Climate Data Analysis Tool (CDAT), the Climate Database Management System (CDMS), and the Visualization and Computation System (VCS) are also high on the list of priorities, but development of other special-purpose software will also be needed. It is the aim of the PCMDI software development team that, with 
the future development of CDAT, CDMS, and VCS, most special-purpose software will be eliminated. Thus, the need to maintain so many software products will be reduced.

\subsection{Short-List of Software Products}

\begin{tabular}{|c|c|c|c|c|}
\hline Name & Acronym & Description & Distributed & Version \\
\hline $\begin{array}{l}\text { Climate Data } \\
\text { Analysis Tool }\end{array}$ & CDAT & $\begin{array}{l}\text { Utilizes an interpreted language to } \\
\text { manipulate data and provide } \\
\text { climate scientists with diagnostic, } \\
\text { statistical, and regridding routines. }\end{array}$ & Internally & Beta \\
\hline $\begin{array}{l}\text { Climate } \\
\text { Database } \\
\text { Management } \\
\text { System }\end{array}$ & CDMS & $\begin{array}{l}\text { Designed to automatically locate } \\
\text { and extract metadata (i.e., } \\
\text { variables, dimensions, grids, etc.) } \\
\text { from PCMDI's collection of } \\
\text { model runs and analysis files. }\end{array}$ & Internally & Beta \\
\hline $\begin{array}{l}\text { Common Data } \\
\text { UNIform File }\end{array}$ & cdunif & $\begin{array}{l}\text { A library of input functions for } \\
\text { accessing netCDF, HDF, DRS, } \\
\text { GrADS/GRIB and VPOP data } \\
\text { files. }\end{array}$ & Externally & 1.7 \\
\hline $\begin{array}{l}\text { Data and } \\
\text { Dimension } \\
\text { Interface }\end{array}$ & DDI & $\begin{array}{l}\text { A Graphical User Interface (GUI) } \\
\text { that reads and writes available file } \\
\text { formats, and sends data to a } \\
\text { variety of visualization systems. }\end{array}$ & Externally & 1.2 \\
\hline $\begin{array}{l}\text { Data Retrieval } \\
\text { and Storage }\end{array}$ & DRS & $\begin{array}{l}\text { A library that supports direct } \\
\text { access } \mathrm{I} / \mathrm{O} \text {, and multi-dimensional } \\
\text { array variables. }\end{array}$ & Externally & 1.5 \\
\hline EzGet & & $\begin{array}{l}\text { A FORTRAN application } \\
\text { programmer's interface (API) for } \\
\text { reading various data file formats } \\
\text { via cdunif, and for performing grid } \\
\text { transformations, data masking, and } \\
\text { some calculations. }\end{array}$ & Externally & 1.1 \\
\hline $\begin{array}{l}\text { Library of } \\
\text { AMIP Data } \\
\text { Transmission } \\
\text { Standards }\end{array}$ & LATS & $\begin{array}{l}\text { A collection of software routines } \\
\text { to output gridded data in either } \\
\text { netCDF or GRIB formats for the } \\
\text { Atmospheric Model } \\
\text { Intercomparison Project (AMIP). }\end{array}$ & Externally & 1.1 \\
\hline $\begin{array}{l}\text { Quality } \\
\text { Control } \\
\text { Software }\end{array}$ & QCS & $\begin{array}{l}\text { Software that checks the } \\
\text { correctness of AMIP model data. }\end{array}$ & Internally & Beta \\
\hline $\begin{array}{l}\text { Visualization } \\
\text { \& Computation } \\
\text { System }\end{array}$ & VCS & $\begin{array}{l}\text { A graphics software package that } \\
\text { allows the display, animation, and } \\
\text { manipulation of scientific data. }\end{array}$ & Externally & 2.7 \\
\hline
\end{tabular}


The PCMDI software products can be represented in levels as shown in Figure 1. The figure shows the foundation-, intermediate-, and top-level design of the PCMDI software system. Although each of the top-level applications are standalone, they can also be used by other PCMDI applications directly or indirectly, thus making the system flexible to individual user preferences.

\section{Levels of PCMDI Software System}

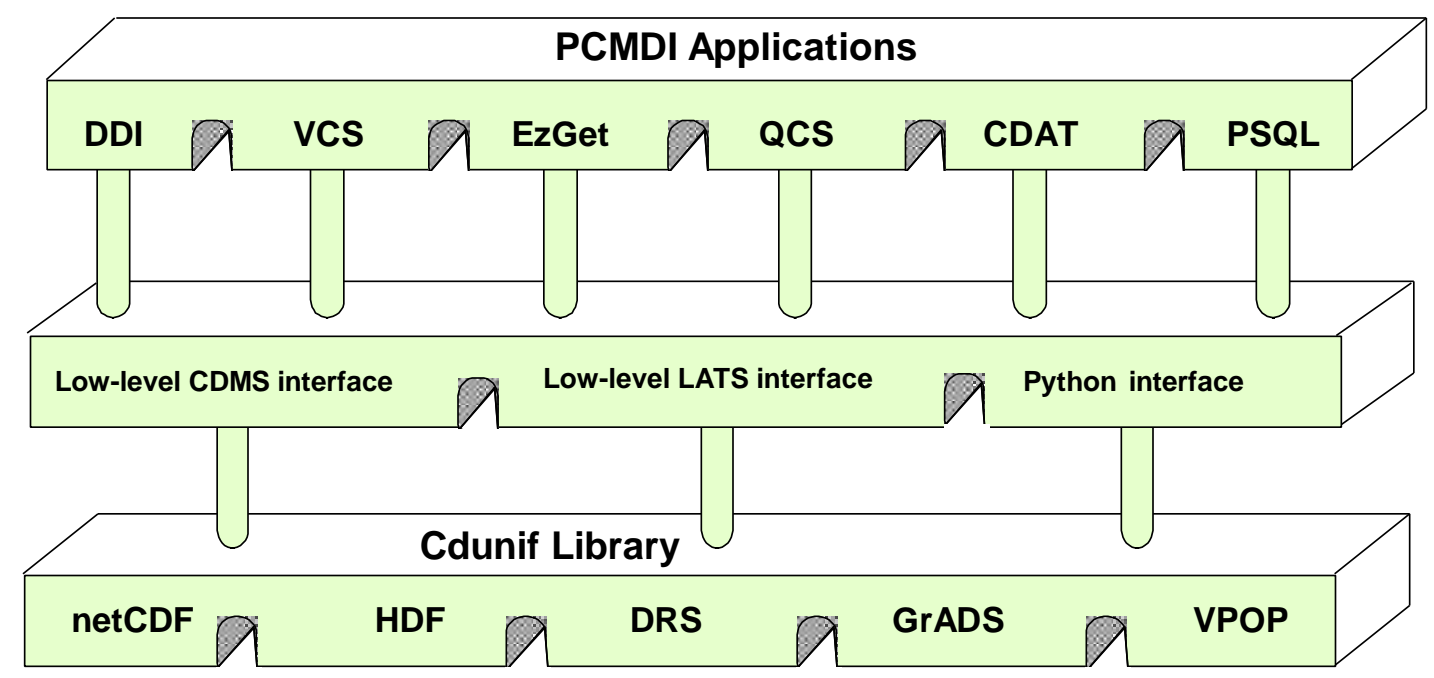

Figure 1. A building block look at the design structure of the PCMDI Software system.

\subsection{Detailed Description of PCMDI Software Products}

\subsubsection{Climate Data Analysis Tool (CDAT)}

\section{CDAT Problem Statement}

A basic problem facing climate scientists is not the absence of software to analyze data, but rather a shortage of interrelated diagnostic tools that are consistent, flexible, portable, adaptable, efficient, share data, and easy to use. Consequently, many scientists are writing their own programs to ingest, manipulate and display their data. Redundancy in such efforts diverts time for the debugging and enhancing of these programs that otherwise would be spent on research. The resulting software is often not user-friendly, reusable, or portable, and does not promote common standards within the climate community. 
Another obstacle to sharing analysis software is the wide variety of data file formats that are in use, making it necessary to write programs to convert data to a user's preferred file format and conventions. This data conversion requires additional expenditure of efforts on testing and quality assurance. Modular and interrelated software to perform such tasks transparently would thus be a valuable asset, allowing climate scientists to spend their time analyzing rather than processing data.

\section{CDAT Purpose}

CDAT provides the climate scientist with an easy and fast method to read different file formats (via cdunif) and to analyze data. It includes a set of predefined functions to allow the user to manipulate the data and send the output to a file which can be viewed as an image, or as a collection of animated images. CDAT also has a gradual learning curve, allowing the novice user to quickly obtain useful results.

\section{CDAT Requirements}

CDAT uses software that has been developed mainly at PCMDI, NCAR, and LANL. Using Python--an interpreted, object-oriented scripting language--as its centralized control module, CDAT is designed to interact with other PCMDI software products. By using Python, CDAT will fulfill the necessary requirements: a standard mathematical library and logical operators, graphics capabilities, scripting language, API, application and user extensibility, and World-Wide Web access.

PCMDI's atmospheric scientists will provide CDAT with diagnostic, statistical, regridding, and units conversion routines. NCAR's CCM model diagnostic routines and LANL's ocean model routines will also be accessible from within CDAT.

CDAT will work as a standalone process and also will be accessible from within CDMS and VCS. All CDAT, CDMS and VCS scripts will be, for the most part, interchangeable.

Users outside PCMDI will be able to access stored data by means of the World Wide Web. Web browsers, such as Netscape and Internet Explorer, will allow outside collaborators to search PCMDI's database, access variables, manipulate data, and display the necessary information. 


\section{CDAT Design Diagram}

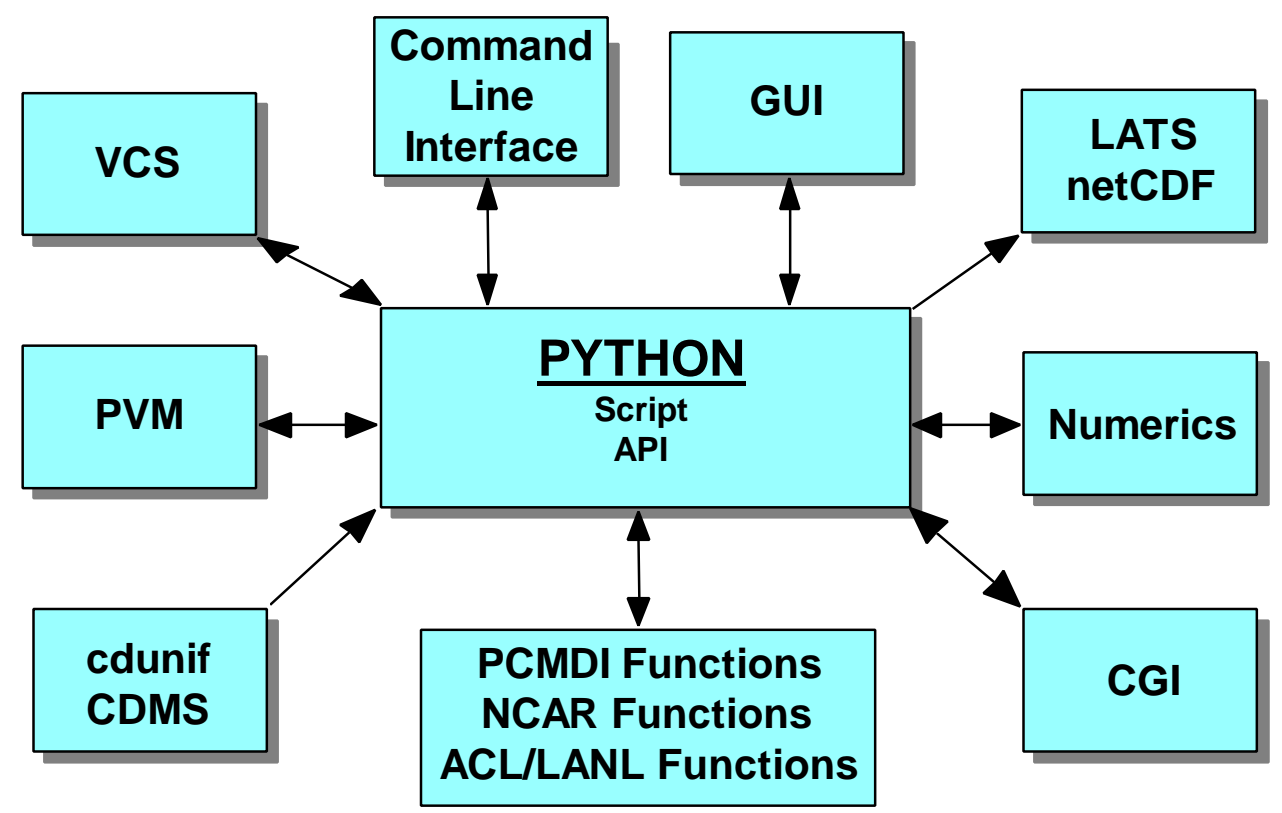

Williams/AMM 8/97 fig.2

Figure 2. Conceptual view of CDAT's modular design.

\section{CDAT Design Diagram Modules}

\begin{tabular}{|l|l|}
\hline Module & \multicolumn{1}{c|}{ Definition/Function } \\
\hline Python & $\begin{array}{l}\text { An interpreted, object-oriented scripting language that allows the user to call CDAT } \\
\text { scripts and use CDAT API commands. }\end{array}$ \\
\hline GUI & $\begin{array}{l}\text { Allows the user to access CDAT from a point-and-click environment. From this } \\
\text { environment the user also has the ability to access the Command Line Interface. }\end{array}$ \\
\hline $\begin{array}{l}\text { Command } \\
\text { Line } \\
\text { Interface }\end{array}$ & $\begin{array}{l}\text { Allows the user to interact with CDAT by entering commands or creating, modifying, } \\
\text { and/or running scripts. This interface also allows the Colormap Editor and Animation } \\
\text { Interface GUIs to appear on the screen. }\end{array}$ \\
\hline $\begin{array}{l}\text { LATS/ } \\
\text { netCDF }\end{array}$ & $\begin{array}{l}\text { LATS allows users to save manipulated data in the PCMDI convention standards. LATS } \\
\text { format options for saving data are either netCDF or GrADS/GRIB. For those not wishing } \\
\text { to save data in PCMDI's convention standards, the option of raw netCDF output is } \\
\text { provided. }\end{array}$ \\
\hline Numerics & Supplies CDAT with trigonometric functions, fast Fourier transforms, eigenvectors, etc. \\
\hline CGI & $\begin{array}{l}\text { This interface provides CDAT with the ability to browse PCMDI's database, access } \\
\text { variables, manipulate data, and display the results via a Web browser. }\end{array}$ \\
\hline PCMDI & The most commonly used PCMDI diagnostic and statistical functions included in CDAT. \\
\hline
\end{tabular}




\begin{tabular}{|l|l|}
\hline Functions & \\
\hline $\begin{array}{l}\text { NCAR } \\
\text { Functions }\end{array}$ & NCAR's CCM atmospheric diagnostic functions. \\
\hline $\begin{array}{l}\text { ACL/ } \\
\text { LANL }\end{array}$ & ACL/LANL's ocean diagnostic functions. \\
\hline cdunif & $\begin{array}{l}\text { Allows CDAT access to many types of data file formats (i.e., netCDF, HDF, DRS, } \\
\text { GrADS, and GRIB). }\end{array}$ \\
\hline CDMS & $\begin{array}{l}\text { Allows CDAT to automatically locate and extract physics quantities (i.e., variables, } \\
\text { dimensions, grids, etc.). }\end{array}$ \\
\hline PVM & $\begin{array}{l}\text { PVM is a software system that allows you to combine a number of computers which are } \\
\text { connected over a network into a parallel virtual machine. This machine can consist of } \\
\text { computers with different architectures, running different flavors of the UNIX operating } \\
\text { systems and can still be treated as if it were a single parallel machine. }\end{array}$ \\
\hline VCS & Allows CDAT users the ability to display and animate scientific data. \\
\hline
\end{tabular}

\section{CDAT Current Status}

\begin{tabular}{|l|l|}
\hline \multicolumn{1}{|c|}{ Module } & \multicolumn{1}{c|}{ Status } \\
\hline Python & Completed. \\
\hline Command Line Interface & Completed, may need modifications. \\
\hline Graphical User's Interface & Needs design and development. \\
\hline LATS & Completed. \\
\hline netCDF & Completed. \\
\hline Numerics & Modifications are necessary. \\
\hline Common Graphical Interface & Needs design and development. \\
\hline PCMDI Functions & Under development, currently implementing regridder. \\
\hline NCAR Functions & Needs design and development. \\
\hline LANL Functions & Needs design and development. \\
\hline cdunif & Connections to completed. \\
\hline CDMS & Needs design and development. \\
\hline VCS & Completed, may need modifications. \\
\hline Documentation & Incomplete, further documentation is necessary. \\
\hline
\end{tabular}

CDAT is scheduled for beta release in August, 1997. Beta release will feature: Python Numeric Functions, Command Line Interface, LATS, netCDF, cdunif, and VCS modules. It also will contain one PCMDI function (i.e., re-grid function developed by Karl Taylor and Clyde Dease), and limited documentation.

\subsubsection{Climate Database Management System (CDMS)}

\section{CDMS Problem Statement}

PCMDI is facing a data storage dilemma. Currently, climate scientists are storing data on PCMDI's UNIX server disk space (i.e., /scratch) and at the National Energy Research 
Supercomputing Center (NERSC) on PCMDI's storage archive. In addition, scientists also are storing data there on local disk space. Having data in various locations can be confusing and data is often misplaced and lost, costing scientists valuable time searching for or regenerating data.

Having access to someone else's data is also a problem, as it is often hard to understand another methodology for storing or naming data and their attributes. Also, once the data is located, it is often in a different file format, dimension arrangement, or naming convention.

All of the above are a hindrance to effectively using the data, limiting productivity and ability to communicate on all levels of the data.

\section{$\underline{\text { CDMS Purpose }}$}

CDMS is a software tool designed to automatically locate and extract metadata (i.e., variables, dimensions, grids, parameters and attributes, etc.) from PCMDI's collection of model runs and analysis files. Its function will be to keep track of various data files, their contents, and the format (i.e., netCDF, HDF, DRS, GrADS, GRIB) of each data file. CDMS will allow the user to: conceptually reorganize stored data files; navigate and extract data by use of quantity names and/or attributes; conceptually rename file quantities and join quantities that are physically stored across multiple servers and/or files; and reorder and select arbitrary subsets as CDMS transfers data from disk to memory.

CDMS is also designed to include an interactive tool, as well as a callable library, for the maintenance, grouping, locating, and scanning of PCMDI's data analysis files. It also will be used to 'override' incorrect file coordinate values and 'insert' new attribute tags/comments. In addition, users will be able to 'combine' quantities spread across several files into an outwardly appearance single multi-dimensional array, all without physically having to move or modify the actual data analysis files.

In short, CDMS is designed to be the logical storage structure for PCMDI's data management system, providing a relational database to retrieve arbitrary databases, datasets, dimensions, grids, variables, parameters, and attributes. With the completion of CDMS, development of standards

for data archiving, access and exchange will lead to the system integration and documentation of all model and observational climate data sets envisaged by PCMDI.

\section{CDMS Requirements}

CDMS is written entirely in the $\mathrm{C}$ programming language. It provides access to databases through a scripting language, command line user interface, an API, and a GUI. The Structured Query Language (SQL), the accepted universal database language, will be adapted for PCMDI's purposes (designated as PSQL) to allow users to describe a CDMS data set in an intelligible form.

CDMS will work as a standalone process and also will be seamlessly accessible from within CDAT, VCS and other PCMDI applications. All CDAT, CDMS and VCS scripts will be, for the most part, interchangeable. 


\section{CDMS Design Diagram}

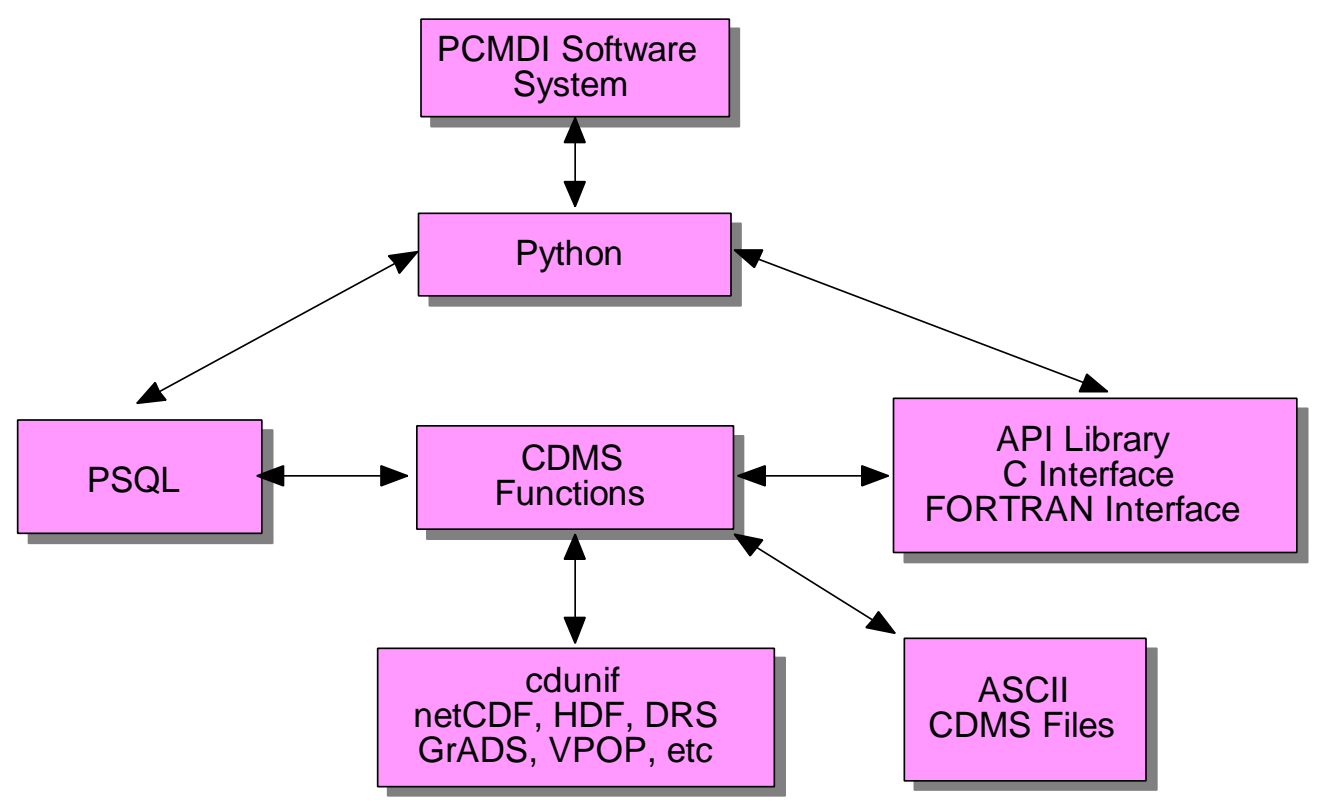

Figure 3. Conceptual view of CDMS's modular design.

\section{CDMS Design Diagram Modules}

\begin{tabular}{|l|l|}
\hline \multicolumn{1}{|c|}{ Module } & \multicolumn{1}{c|}{ Definition/Function } \\
\hline $\begin{array}{l}\text { PCMDI } \\
\text { Software } \\
\text { System }\end{array}$ & $\begin{array}{l}\text { PCMDI's complete software system, consisting mainly of CDAT, PCMDI's } \\
\text { data manipulator; CDMS, PCMDI's database; and VCS PCMDI's } \\
\text { visualization system. }\end{array}$ \\
\hline Python & $\begin{array}{l}\text { An interpreted, object-oriented scripting language that allows the user to call } \\
\text { CDAT scripts and use CDAT API commands. }\end{array}$ \\
\hline $\begin{array}{l}\text { CDMS } \\
\text { Functions }\end{array}$ & Low-level routines that create and queries the database. \\
\hline $\begin{array}{l}\text { API Library } \\
\text { Interface }\end{array}$ & C and FORTRAN libraries that interface into the low-level CDMS Functions. \\
\hline $\begin{array}{l}\text { ASCII } \\
\text { CDMS Files }\end{array}$ & ASCII CDMS database files that user's are allowed to create and manipulate. \\
\hline cdunif & $\begin{array}{l}\text { Allows CDAT access to many types of data file formats (i.e., netCDF, HDF, } \\
\text { DRS, GrADS, and GRIB). }\end{array}$ \\
\hline PSQL & $\begin{array}{l}\text { Command line interface that allows the user to run database commands to } \\
\text { create, modify and query the database. }\end{array}$ \\
\hline
\end{tabular}




\section{$\underline{\text { CDMS Current Status }}$}

\begin{tabular}{|l|l|}
\hline \multicolumn{1}{|c|}{ Module } & \multicolumn{1}{c|}{ Status } \\
\hline $\begin{array}{l}\text { PCMDI Software } \\
\text { System }\end{array}$ & $\begin{array}{l}\text { Under development, completing and integrating } \\
\text { CDAT, CDMS, and VCS together. }\end{array}$ \\
\hline Python & $\begin{array}{l}\text { Connecting CDMS to Python needs to be } \\
\text { developed. }\end{array}$ \\
\hline CDMS Functions & Under development, 60 percent complete. \\
\hline API Library Interface & $\begin{array}{l}\text { C Interface to low-level CDMS functions are 60 } \\
\text { percent complete. FORTRAN Interface needs to } \\
\text { be designed and developed. }\end{array}$ \\
\hline $\begin{array}{l}\text { ASCII CDMS Meta } \\
\text { Descriptive Data Files }\end{array}$ & Completed, may need modifications. \\
\hline cdunif & Connections to CDMS Completed. \\
\hline PSQL & $\begin{array}{l}\text { PSQL is completed, may need additional functions } \\
\text { added to the database. }\end{array}$ \\
\hline Documentation & Incomplete, documentation is 10 percent complete. \\
\hline
\end{tabular}

\subsubsection{Climate Data UNIform File (cdunif) Reader}

\section{Cdunif Problem Statement}

As a participant in the international climate community, PCMDI receives and sends climate data in many different formats, requiring the ongoing transformation of others' data to fit one's own application. This often leads to data conversion errors, data duplication, and use of large amounts of disk space. Data conversion also is expensive and time consuming; as a result, some scientific investigations in the past have been abandoned.

Figure 4 shows a hypothetical 4D data set that may have been received. Note, data can be received as a $1 \mathrm{D}, 2 \mathrm{D}, \ldots$, up to $128 \mathrm{D}$ data set. The figure below is just to give a perspective view of our concept of a data array. 


\section{The Contents of a Four-Dimensional Data Set}

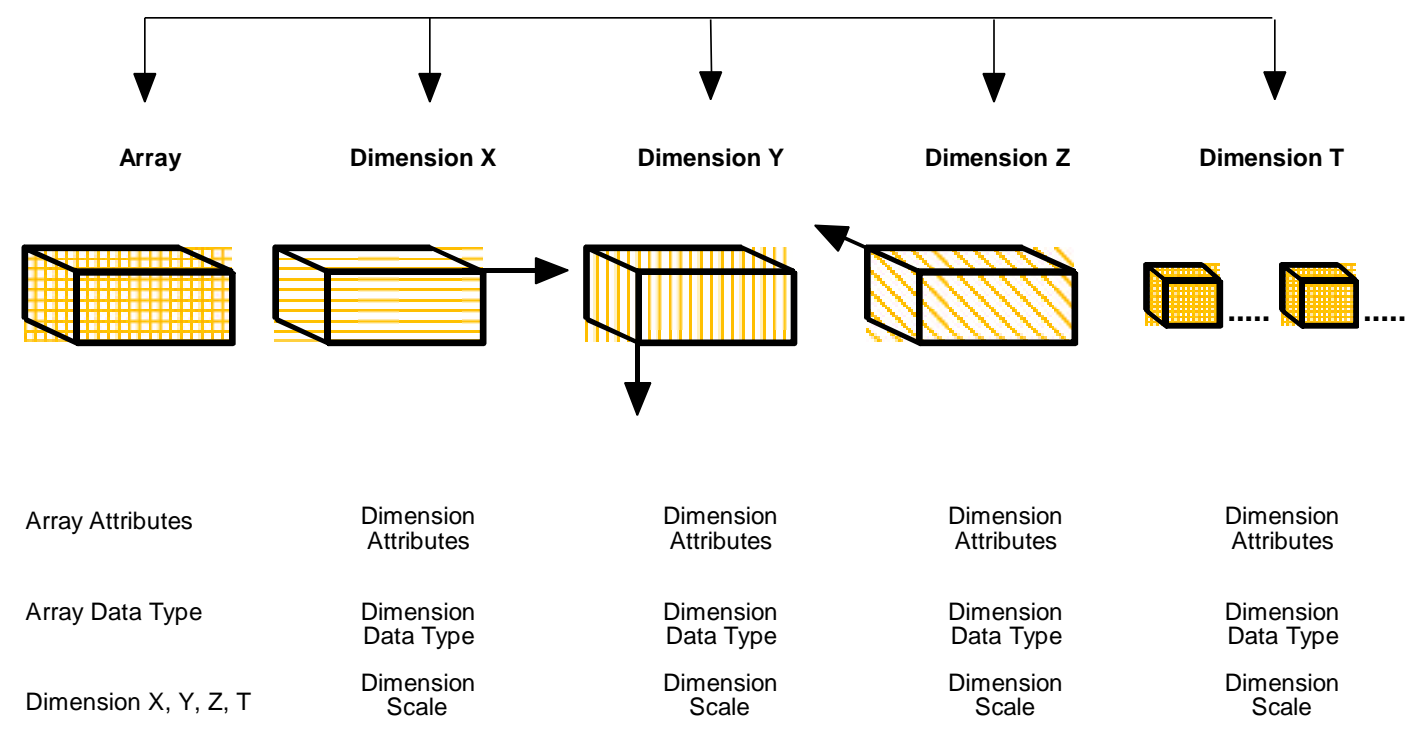

Figure 4. A conceptual look at a hypothetical array data.

\section{Cdunif Purpose}

Cdunif is an API library that allows programs to read many different structured data files without concern for their actual file format. Presently, cdunif includes a collection of uniform input/output (I/O) routines for accessing netCDF, HDF, DRS, GrADS, and VPOP file formats. Through the GrADS control file, GRIB files also can be read. Cdunif will be designed to accommodate other structured data file formats, as needed by the climate community.

All major PCMDI software products will use cdunif to ingest data directly or indirectly via CDMS.

\section{$\underline{\text { Cdunif Requirement }}$}

The cdunif interface is modeled very closely after the UCAR netCDF interface. In most cases, cdunif functions are identical in everything except name to analogous netCDF functions. The logical model for metadata in cdunif also will be very similar to netCDF. A file contains a set of variables, dimensions, and attributes. Variables will be identified by integer ID or name; variable IDs range from 0 to $\mathrm{N}-1$, where $\mathrm{N}$ is the number of variables. Attributes also are identified by number or name, and can either be global or variable-specific.

Dimensions will be treated somewhat differently than in netCDF. Some of the file formats supported by cdunif, notably the Data Retrieval and Storage (DRS) format, support dimensions 
which are local to a given variable; they are not shared by different variables and do not have unique names relative to other dimensions. Consequently, a distinction is made between local and global dimensions, where the latter can be shared. (DRS vector dimensions are global.)

Every dimension also has an associated coordinate vector, which can be retrieved by the cudimget function. Like netCDF, dimensions are identified by name or numeric ID; both local and global dimensions have unique numeric IDs, which are sequential integers starting at 0 .

The cdunif interface supports the data types corresponding to the $\mathrm{C}$ programming language: byte, character, short, integer, long, float, double, and long double. The cdunif functions are accessible from both C and FORTRAN programs via different API's, but contain identical function calls and parameter values. The APIs will allow the user to open and close files, to inquire about variables and dimensions and attributes, and to read data in a way that is user-specific (e.g., wrapped, transposed, reversed, etc.).

In compliance with the Cooperative Ocean/Atmosphere Research Data Service (COARDS) convention, cdunif can read data that has "missing_value", "add_offset", and "scale_factor" attributes set for the variable.

\section{Cdunif Design Diagram}

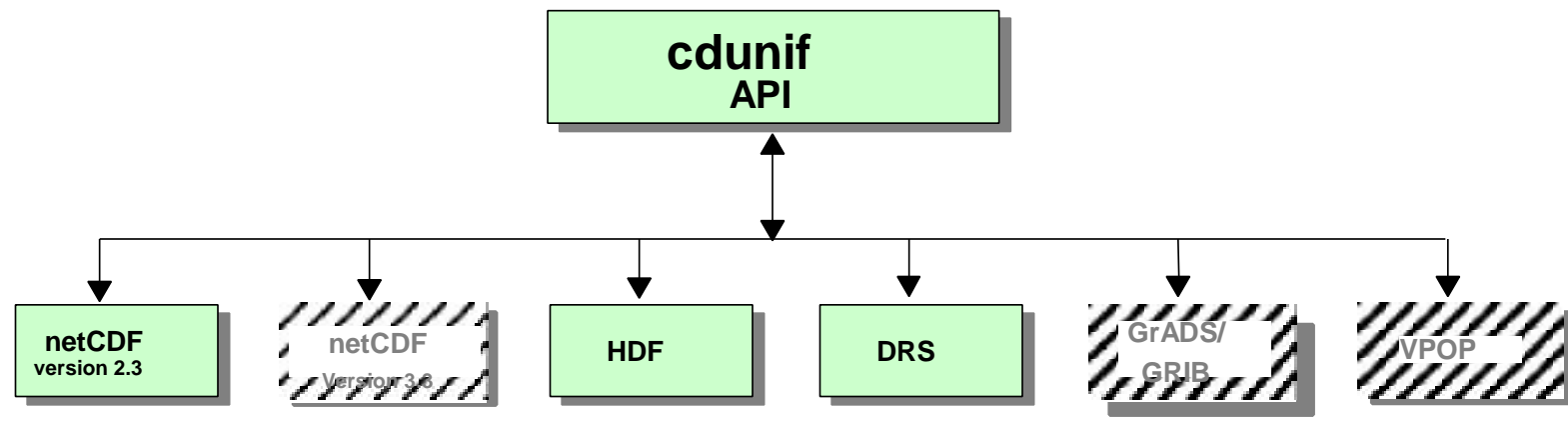

Figure 6. Conceptual view of cdunif's modular design. 


\section{$\underline{\text { Cdunif Design Diagram Modules }}$}

\begin{tabular}{|l|l|}
\hline \multicolumn{1}{|c|}{ Module } & \multicolumn{1}{c|}{ Definition/Function } \\
\hline cdunif API & $\begin{array}{l}\text { Provides a C and FORTRAN application programmer's interface to } \\
\text { low-level cdunif functions (i.e., open and close a file, inquire file } \\
\text { information, read data, etc.). }\end{array}$ \\
\hline $\begin{array}{l}\text { netCDF } \\
\text { version 2.3 }\end{array}$ & NetCDF library version 2.3, reads data bit-by-bit via XDR. \\
\hline $\begin{array}{l}\text { netCDF } \\
\text { version 3.3 }\end{array}$ & $\begin{array}{l}\text { NetCDF library version 3.3, reads data differently via mmap. This } \\
\text { may speed up the ingest process of netCDF files. }\end{array}$ \\
\hline HDF & $\begin{array}{l}\text { HDF library allows cdunif to ingest HDF files that were created with } \\
\text { HDF version 3.0 or higher. }\end{array}$ \\
\hline DRS & DRS library allows cdunif to ingest DRS files. \\
\hline GrADS/GRIB & $\begin{array}{l}\text { GrADS/GRIB is a series of C routines that read GrADS files into } \\
\text { cdunif. Through a GrADS control file cdunif can read GRIB data. }\end{array}$ \\
\hline VPOP & VPOP is a library that allows access to LANL's ocean data. \\
\hline
\end{tabular}

\section{Cdunif Current Status}

\begin{tabular}{|l|l|}
\hline \multicolumn{1}{|c|}{ Module } & \multicolumn{1}{c|}{ Status } \\
\hline cdunif API & $\begin{array}{l}\text { C interface is complete. FORTRAN interface complete, but may } \\
\text { need modifications. cuhyperslab (allows the user to transpose, } \\
\text { reverse, sub-set, and wrap data) - completed but may need } \\
\text { modifications. }\end{array}$ \\
\hline $\begin{array}{l}\text { netCDF } \\
\text { version 2.3 }\end{array}$ & Completed. \\
\hline $\begin{array}{l}\text { netCDF } \\
\text { version 3.3 }\end{array}$ & Needs development. \\
\hline HDF & Completed. \\
\hline DRS & Completed. \\
\hline GrADS/GRIB & Needs further development. \\
\hline VPOP & Needs development. \\
\hline Documentation & 50 percent complete. \\
\hline
\end{tabular}

The next version of cdunif, scheduled for beta release in September 1997, will feature: HDF, VPOP, newer version of GrADS/GRIB, the cuhyperslab function, and attribute manipulation of the data (e.g., "add_offset", "missing_value", and "scale_factor"). 


\subsubsection{Data and Dimension (DDI)}

\section{DDI Problem Statement}

The Data and Dimensions Interface (DDI) addresses a significant problem in the visualization of large data sets: the need to extract only the relevant data and to readily provide these in the required form to a chosen graphics engine.

Many different research communities have developed formats for storing and retrieving scientific data and their associated metadata. These formats, while similar in their intent, are often incompatible, and their lack of support by commercial visualization systems has been an impediment to their widespread use. Accessing large data files has also proven problematical.

Sometimes generated on supercomputers, these data often are visualized on smaller platforms (i.e., workstations, PCs, etc.), with the data transfer being implemented either by copying to disk or by use of the Internet's File Transport Protocol (FTP). In both cases, the data has lacked solid quality-control.

\section{DDI Purpose}

DDI transfers data between files, formats and visualization systems.

\section{DDI Requirements}

DDI works within the specifications of each supported format to promote compatibility and provide the following capabilities:

- Browsing the contents of files written in a variety of formats;

- Randomly selecting data variables;

- Rearranging variables into the desired form;

- Modifying the values of certain variable attributes;

- Saving variables to new files;

- Feeding variables directly to a visualization system.

DDI operates in two modes:

- As a module in a data flow environment;

- As a stand-alone application capable of sending data over the network.

Presently, DDI is able to transfer variables to the following visualization systems:

- The PCMDI Visualization and Computation System (VCS);

- The Applications Visualization System (AVS), from Advanced Visual Systems Inc.;

- Collage and XImage, from the National Center for Supercomputer Applications (NCSA);

- The Interactive Data Language (IDL) from Research Systems, Inc.;

- IRIS Explorer, from Silicon Graphics Inc.;

- PV-WAVE, from Visual Numerics Inc.

- Khoros, from Khoral Research, Inc. 


\section{DDI Design Diagram}

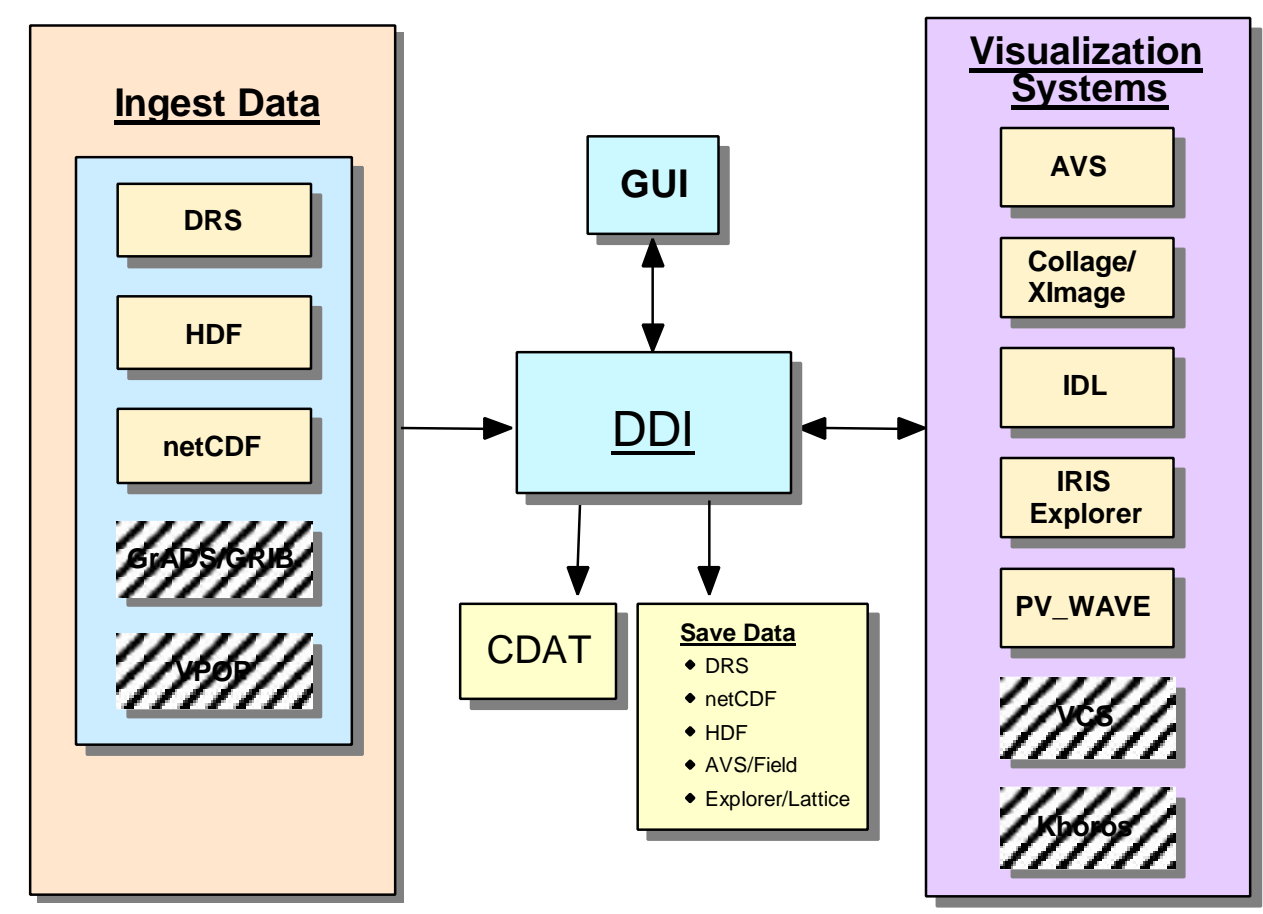

Williams/AMM $8 / 11 / 97 \quad d w 13$

Figure 7. Conceptual view of DDI's modular design.

\section{DDI Design Diagram Modules}

\begin{tabular}{|l|l|}
\hline \multicolumn{1}{|c|}{ Module } & \multicolumn{1}{c|}{ Definition/Function } \\
\hline DDI & $\begin{array}{l}\text { Performs data operations, such as: transformation of the data; reversal } \\
\text { and scaling of coordinate values; modification, creation, and removal of } \\
\text { attributes; export of data to visualization engines. }\end{array}$ \\
\hline GUI & $\begin{array}{l}\text { Allows data access and access to visualization systems via a point-and- } \\
\text { click interface. }\end{array}$ \\
\hline AVS & $\begin{array}{l}\text { Allows sending of data to AVS directly, where DDI is a module in the } \\
\text { AVS data flow environment, or indirectly using UNIX sockets. }\end{array}$ \\
\hline $\begin{array}{l}\text { Collage/ } \\
\text { XImage }\end{array}$ & $\begin{array}{l}\text { Allows sending of data indirectly to the NCSA visualization tools, using } \\
\text { UNIX sockets. }\end{array}$ \\
\hline IDL & Allows the sending of data indirect to IDL, using UNIX sockets. \\
\hline IRIS Explorer & $\begin{array}{l}\text { Allows the sending of data to Explorer directly, where DDI is a module } \\
\text { in the Explorer data flow environment, or indirectly using UNIX } \\
\text { sockets. }\end{array}$ \\
\hline Khoros & $\begin{array}{l}\text { Allows the sending of data to Khoros directly, where DDI is a module } \\
\text { in the Khoros data flow environment, or indirectly using UNIX sockets. }\end{array}$ \\
\hline
\end{tabular}




\begin{tabular}{|l|l|}
\hline PV-WAVE & $\begin{array}{l}\text { Allows the sending of data to PV-WAVE indirectly using UNIX } \\
\text { sockets. }\end{array}$ \\
\hline VCS & Allows the sending of data indirectly to VCS using UNIX sockets. \\
\hline Save Data & $\begin{array}{l}\text { Allows the saving of data in five file formats: DRS, netCDF, HDF, } \\
\text { AVS/Field, and Explorer/Lattice. }\end{array}$ \\
\hline Ingest Data & $\begin{array}{l}\text { Allows the ingesting of data in five file formats: DRS, GrADS/GRIB, } \\
\text { HDF, netCDF, and VPOP. }\end{array}$ \\
\hline
\end{tabular}

\section{DDI Current Status}

\begin{tabular}{|l|l|}
\hline \multicolumn{1}{|c|}{ Module } & \multicolumn{1}{c|}{ Status } \\
\hline DDI & Completed. \\
\hline GUI & Completed. \\
\hline AVS & Completed. \\
\hline College/XImage & Completed. \\
\hline IDL & Completed. \\
\hline IRIS Explorer & Completed. \\
\hline PV-WAVE & Completed. \\
\hline VCS & Needs design and development. \\
\hline Khoros & Needs design and development. \\
\hline Ingest Data & $\begin{array}{l}\text { Incomplete, needs access to cdunif module. By accessing the } \\
\text { cdunif module, DDI will be able to ingest GrADS/GRIB and } \\
\text { VPOP data. }\end{array}$ \\
\hline
\end{tabular}

DDI version 1.2 is currently released to PCMDI users and to the public.

\subsubsection{Data Retrieval and Storage (DRS)}

\section{$\underline{\text { DRS Problem Statement }}$}

Prior to the 1990's, climate scientists commonly stored data in a FORTRAN binary or ASCII file, with metadata also in ASCII. This method was problematical when porting data from a supercomputer to a workstation, but later the cross-platform issue was solved by the introduction of the IEEE standard file format. However, the exchange of scientific data remained difficult due to the difficulties of reading different file formats. This problem is alleviated by the Data Retrieval and Storage (DRS) library and utilities developed by PCMDI.

\section{DRS Purpose}

The DRS (Data Retrieval and Storage) library and utilities support the scientific data format used at PCMDI as well as the high-volume multi-dimensional array output from global climate models. Presently, DRS runs on the following platforms: Cray/UNICOS, Sun/SunOS 4.1.3, Sun/Solaris 2.4, SGI IRIX 5.3, IBM RS6000/AIX 3.2, DEC Alpha/OSF, HP/HP-UX 9.0, and Linux/PC. 


\section{DRS Requirements}

Notable features of the DRS system include:

- support for multi-dimensional array variables

- sub-setting and data reordering operations

- direct access I/O, and access by coordinate ranges

- machine-independent format

- support for Cray native mode

- $\mathrm{C}$ and FORTRAN APIs

- interactive data browser utility

\section{DRS Design Diagram}

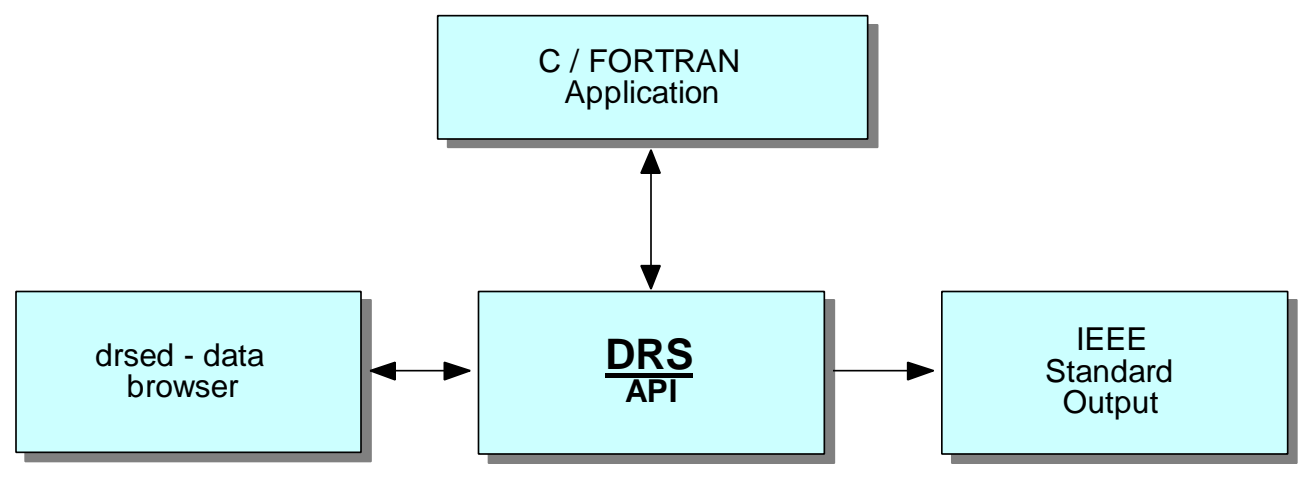

Williams/AMM
$8 / 12 / 97$ dw9

Figure 8. Conceptual view of DRS's modular design.

\section{DRS Design Diagram Modules}

\begin{tabular}{|l|l|}
\hline \multicolumn{1}{|c|}{ Module } & \multicolumn{1}{c|}{ Definition/Function } \\
\hline DRS & $\begin{array}{l}\text { Provides a C and FORTRAN application programmer's interface } \\
\text { to low-level DRS functions (i.e., open and close a file, inquire } \\
\text { file information, read data, write data, etc.). }\end{array}$ \\
\hline $\begin{array}{l}\text { C/FORTRAN } \\
\text { Application }\end{array}$ & C or FORTRAN program that calls DRS functions via the API. \\
\hline Drsed data browser & Utility program that browses DRS files. \\
\hline DRS Output & $\begin{array}{l}\text { Saves data in IEEE standard output. This allows the data to be } \\
\text { read on different platforms. }\end{array}$ \\
\hline
\end{tabular}




\section{DRS Current Status}

\begin{tabular}{|l|l|}
\hline Module & Status \\
\hline DRS & $\begin{array}{l}\text { Completed. May need to port to } \\
\text { different platforms. }\end{array}$ \\
\hline Drsed - data browser & Completed. \\
\hline
\end{tabular}

DRS version 1.6 is currently released to PCMDI users and to the public.

\subsubsection{EzGet}

\section{EzGet Problem Statement}

After the inception of DRS, the need for extensions of this data access software became apparent. These include the need for better error trapping capabilities and more detailed error messages; for more convenient ways to select data from specified regions (e.g., "Oceans", "North America", all land areas north of 45 degrees latitude, etc.); for the ability to map data to a new grid at the time it is retrieved; for automatic creation of "weights" used in subsequent averaging or masking of data; for automatic retrieval of all dimension information; and for increased control in specifying the domain, grid and structure of the retrieved data.

\section{EzGet Purpose}

EzGet (pronounced "Easy-Get") was developed to meet the needs noted above. It serves a different purpose from other software tools developed at PCMDI in that, unlike DDI and VCS, EzGet comprises a set of subroutines that can be linked to any FORTRAN program. The software accesses data stored in file formats that are readable by the cdunif FORTRAN API; however, use of EzGet does not require knowledge of cdunif.

\section{EzGet Requirements}

EzGet is written in FORTRAN, the programming language most familiar to climate scientists. However, to comply with the overall design of the PCMDI software system, many of EzGet's functions will be incorporated into CDAT. 


\section{EzGet Design Diagram}

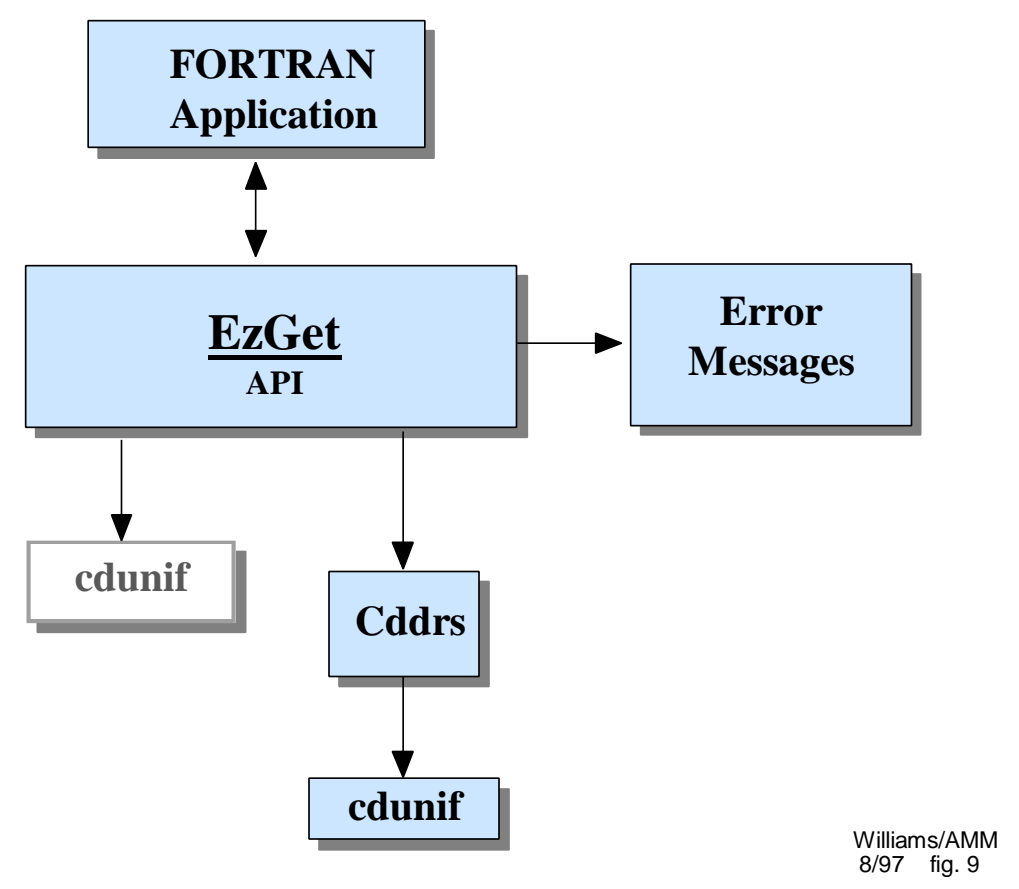

Figure 9. Conceptual view of EzGet's modular design.

\section{EzGet Design Diagram Modules}

\begin{tabular}{|l|l|}
\hline \multicolumn{1}{|c|}{ Module } & \multicolumn{1}{c|}{ Definition/Function } \\
\hline EzGet & $\begin{array}{l}\text { Provides the user with a FORTRAN API that has substantial error } \\
\text { trapping capabilities, the capability of selecting data from specified } \\
\text { regions, the ability to map data to a new grid, the creation of average } \\
\text { weights, and the automatic retrieval of all dimension information. }\end{array}$ \\
\hline $\begin{array}{l}\text { Standard } \\
\text { Output }\end{array}$ & Error Messages. \\
\hline Cddrs & $\begin{array}{l}\text { Indirect connection to cdunif. It uses the DRS API to feed } \\
\text { information to cdunif. }\end{array}$ \\
\hline $\begin{array}{l}\text { FORTRAN } \\
\text { Application }\end{array}$ & User specified FORTRAN program. \\
\hline cdunif & $\begin{array}{l}\text { Allows EzGet access to many types of data file formats (i.e., netCDF, } \\
\text { HDF, DRS, GrADS, and GRIB). }\end{array}$ \\
\hline
\end{tabular}




\section{$\underline{\text { EzGet Current Status }}$}

\begin{tabular}{|l|l|}
\hline \multicolumn{1}{|c|}{ Module } & \multicolumn{1}{c|}{ Status } \\
\hline EzGet & Completed. \\
\hline Standard Output & Completed. \\
\hline Cddrs & Completed. \\
\hline cdunif & $\begin{array}{l}\text { Direct cdunif connection to EzGet is incomplete. Design } \\
\text { and Development is necessary. }\end{array}$ \\
\hline
\end{tabular}

EzGet version 1.0 is currently released to PCMDI users and to the public.

\subsubsection{Library of AMIP Data Transmission (LATS)}

\section{LATS Problem Statement}

A library of software routines to output gridded data in the COARDS convention is needed to simplify the processing of voluminous data from the next phase of the AMIP (denoted as AMIP II) and other model intercomparison projects.

\section{LATS Purpose}

LATS is a library of software routines for output of gridded data that was developed by PCMDI in support of AMIP II and other intercomparison projects. The primary function of LATS will be to establish and implement a convention/standard for gridded data, and thus facilitate data handling and exchange. The LATS API, which is designed to be simple to understand and use, provides FORTRAN and $\mathrm{C}$ interfaces.

LATS applications can output data in either the WMO GRIdded Binary (GRIB) format or in the netCDF format under the COARDS convention.

\section{LATS Requirements}

LATS is not considered to be a general purpose gridded data output system; rather, it operates within the following design constraints:

- Simple to use

- Multi-platform

- Targeted for global climate model output (currently limited to use with rectilinear data)

- Implementing COARDS conventions for data and metadata

- Using two well-established and commonly used data formats

- Software to be made available in the public domain.

LATS outputs rectilinear, gridded, spatio-temporal data written in either GRID or netCDF formats that are machine-independent. The fundamental unit of data written with a single 
function is known as a horizontal longitude-latitude slice of a variable. However, derivative structures such as zonal mean-height cross sections (i.e., a sequence of single-longitude, multiplelatitude grids) are also supported.

LATS maintains an internal parameter table that prescribes variable names, description, units, datatype, basic structure (e.g., upper air or surface), and compression (GRIB options). These descriptors are inferred from the parameter name only. Thus, most of the metadata needed to write GRIB and/or netCDF data are located in the parameter table to simplify the API. An option also is provided to override the internal table with an external parameter file.

LATS parameter tables are designed to fit the specific needs of climate model intercomparison projects:

- More than one LATS file may be open simultaneously for output;

- For a given time point, multiple variables and variables at multiple levels may be written in any order;

- Data can only be written in increasing time sequence;

- All data are floating-point or integer. Only FORTRAN REALS (C floats) and INTEGERS (C ints) are written.

\section{LATS Design Diagram}

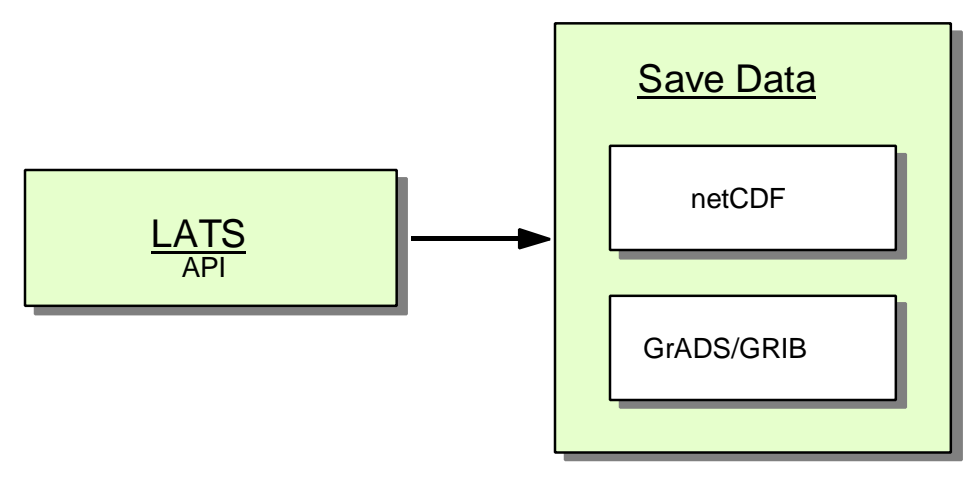

Figure 10. Conceptual view of LATS's modular design. 


\section{$\underline{\text { LATS Design Diagram Modules }}$}

\begin{tabular}{|l|l|}
\hline \multicolumn{1}{|c|}{ Module } & \multicolumn{1}{c|}{ Definition/Function } \\
\hline LATS & $\begin{array}{l}\text { Contains functions to save data in the COARDS } \\
\text { conventions. It also contains a C and FORTRAN API. }\end{array}$ \\
\hline Save Data & Saves data in either netCDF or GrADS/GRIB formats. \\
\hline
\end{tabular}

\section{$\underline{\text { LATS Current Status }}$}

\begin{tabular}{|l|l|}
\hline Module & \multicolumn{1}{c|}{ Status } \\
\hline LATS & Completed. \\
\hline Save Data & Completed, but will need work on the GrADS/GRIB API interface. \\
\hline
\end{tabular}

LATS version 1.1 is currently released to PCMDI users and to the public.

\subsubsection{Quality Control Software (QCS)}

\section{QCS Problem Statement}

In AMIP II, PCMDI anticipates the need to process and quality control large data sets from numerous climate models in a relatively short period of time. Past experience suggests that the quality of the data will vary considerably over time and from one modeling group to another. In addition, the large size and variety of the data, the short time frame for their evaluation, and the possibility of errors all demand the development of software to automate the quality control (QC) process.

\section{QCS Purpose}

QCS provides a semiautomatic procedure for quality control of these model output data. The data first are read and organized for evaluation of their consistency, especially with respect to integrity of time sequence. Then the data are rewritten in a standard time series to facilitate the QC process, which consists of two phases. First, the data are subjected to a numerical test for statistical idiosyncrasies; then, VCS plots of specially constructed diagnostics fields are visually inspected to reveal problems not uncovered by the numerical test. As a final step, QCS archives the quality-controlled data in a standard format.

\section{QCS Requirements}

QCS is written in Python with emphasis on the use of other software currently under development, in particular the LATS and cdunif modules that are being coded for CDAT. In addition, QCS has its own math module to implement special calculations needed in the QC process. 


\section{QCS Design Diagram}

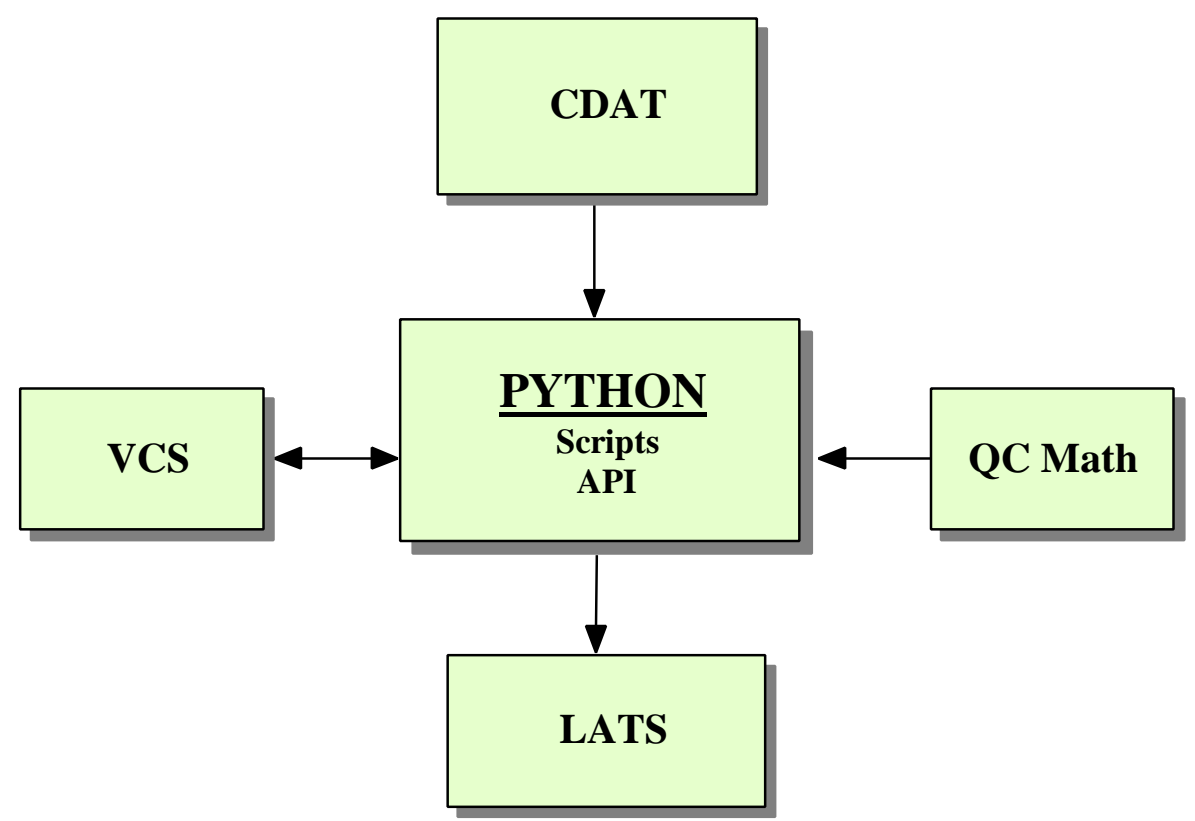

Figure 11. Conceptual view of QCS's modular design.

\section{QCS Design Diagram Modules}

\begin{tabular}{|l|l|}
\hline \multicolumn{1}{|c|}{ Module } & \multicolumn{1}{c|}{ Definition/Function } \\
\hline Python & $\begin{array}{l}\text { An interpreted, object-oriented scripting language that } \\
\text { allows calls to CDAT, QCS, and VCS scripts and also } \\
\text { allows use of API commands for CDAT, QCS, and VCS. }\end{array}$ \\
\hline CDAT & $\begin{array}{l}\text { Provides the diagnostic, statistical, and regridding } \\
\text { routines. }\end{array}$ \\
\hline LATS & $\begin{array}{l}\text { Allows the saving of manipulated data in the PCMDI } \\
\text { convention standards. LATS format options for saving } \\
\text { data are either netCDF or GrADS/GRIB. }\end{array}$ \\
\hline QC Math & $\begin{array}{l}\text { Implements numerical testing of the data for statistical } \\
\text { idiosyncrasies. }\end{array}$ \\
\hline VCS & Allows the display and animation of scientific data. \\
\hline
\end{tabular}




\section{QCS Current Status}

\begin{tabular}{|l|l|}
\hline \multicolumn{1}{|c|}{ Module } & \multicolumn{1}{c|}{ Status } \\
\hline QC Math & $\begin{array}{l}\text { Under development. Once the QC math functions are complete, } \\
\text { then the connections to Python must be implemented. }\end{array}$ \\
\hline Database Inquiry & $\begin{array}{l}\text { Completed. These database inquiries are not to be confused with } \\
\text { CDMS. }\end{array}$ \\
\hline VCS & Completed, may need modifications. \\
\hline LATS & Completed, may need modifications. \\
\hline CDAT & Started, but incomplete. \\
\hline
\end{tabular}

QCS is scheduled for beta test in September, 1997. Beta release of this product will follow that of CDAT.

\subsubsection{Visualization and Computation System (VCS)}

\section{VCS Problem Statement}

The massive amounts ( gigabytes) of data produced by climate model simulations makes imperative the development of powerful visualization tools. Because no single display technique can elucidate all facets of climate model behavior, the visualization system must possess a wide range of graphics capabilities. In comparing simulations from many different models, it is also necessary to perform grid transformations and computations of additional diagnostic variables.

\section{$\underline{\text { VCS Purpose }}$}

The Visualization and Computation System (VCS) is designed to meet the visualization and graphics needs of climate scientists. Because of the breadth of its capabilities, VCS has proven to be a useful tool for other scientific applications as well. VCS allows wide-ranging changes to be made to the data display, provides for hard-copy output and includes a means for recovery of a previous display. VCS also allows the user to browse large amounts of data and obviates the need to create and keep track of intermediate data files.

\section{VCS Requirements}

In the VCS model, the data display is defined by a trio of named attribute sets, designated the "primary elements". They include: the data, which define what to display; the graphics method, which specifies the display technique; and the picture template, which determines the appearance of each segment of the display. 
In addition, detailed specification of the primary elements' attributes are provided by eight "secondary elements":

- colormap: specification of combinations of 256 available colors;

- fill area: style, style index, and color index;

- format: specifications for converting numbers to display strings;

- line: line type, width and color index;

- list: a sequence of pairs of numerical and character values;

- marker: marker type, size, and color index;

- text: text font type, character spacing, expansion and color index;

- text orientation: character height, angle, path, and horizontal/vertical alignment.

By combining primary and secondary elements in various ways (either interactively or in batch mode), the VCS user is able to comprehensively diagnose and intercompare climate model simulations.

VCS provides capabilities to:

- ingest data written in netCDF, HDF, DRS, GrADS, GRIB, or VPOP data file formats

- browse data directories and read these file formats

- quickly display variables via default settings

- view, select and modify attributes of data variables and of their dimensions

- create and modify existing template attributes and graphics methods

- save the state of the system as a script to be run interactively or in batch mode

- save a display as a Computer Graphics Metafile (CGM), raster, or Postscript file

- perform grid transformations and compute new data variables

- create and modify colormaps and zoom into a specified portion of a display or the VCS Canvas

- change the orientation (portrait vs. landscape) or size (partial vs. full-screen) of a display

- animate a single data variable or multiple data variables simultaneously

- save modified data variables in netCDF-, HDF-, or DRS-formatted files 


\section{VCS Design Diagram}

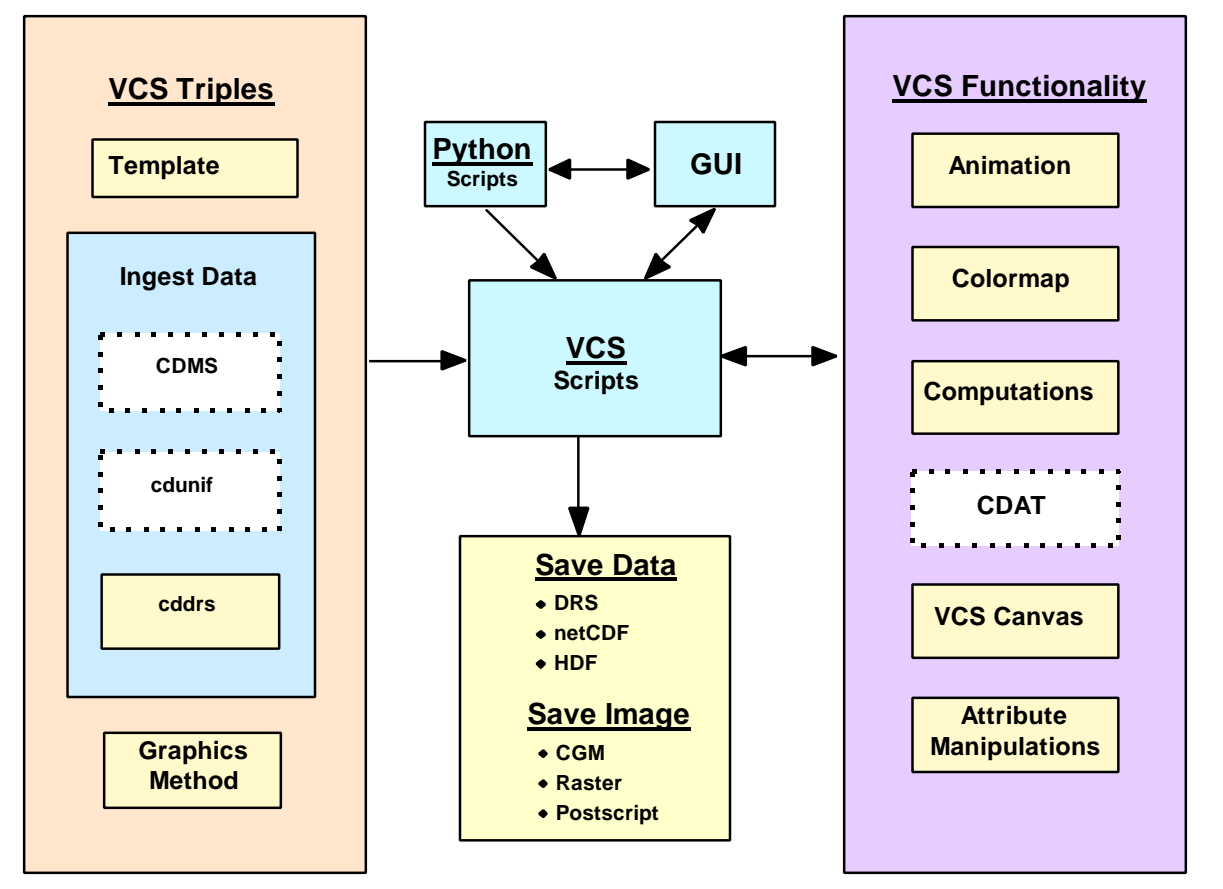

Williams/AMM

Figure 12. Conceptual view of VCS's modular design.

\section{$\underline{\text { VCS Design Diagram Modules }}$}

\begin{tabular}{|l|l|}
\hline \multicolumn{1}{|c|}{ Module } & \multicolumn{1}{c|}{ Definition/Function } \\
\hline VCS & $\begin{array}{l}\text { Contains functions to: create templates, graphics methods, and modify data, } \\
\text { interact with GUI and scripts, animate, compute, change colormaps, save } \\
\text { data, and save images. }\end{array}$ \\
\hline VCS Script & $\begin{array}{l}\text { Allows the saving and running of VCS commands in batch mode or from } \\
\text { the GUI. }\end{array}$ \\
\hline VCS GUI & Allows the user to interface with VCS via a graphical user's interface. \\
\hline VCS Functionality & $\begin{array}{l}\text { VCS functions allow the user to animate data, change the colormaps, } \\
\text { compute data, interface to CDAT, modify the VCS canvas, and change data } \\
\text { attributes. }\end{array}$ \\
\hline Save Data & Saves data in three different file formats: DRS, netCDF, and HDF. \\
\hline Save Image & Saves images in three different formats: CGM, raster, and Postscript. \\
\hline VCS Triples & Defines by a trio of named attributes: data, template, and graphics method. \\
\hline
\end{tabular}




\section{$\underline{\text { VCS Current Status }}$}

\begin{tabular}{|l|l|}
\hline \multicolumn{1}{|c|}{ Module } & \multicolumn{1}{c|}{ Status } \\
\hline VCS & Completed. \\
\hline VCS Scripts & Completed, may need modifications. \\
\hline VCS GUI & Completed, will need modifications. \\
\hline VCS Functionality & Completed, may need modifications. \\
\hline Save Data & Completed, may need modifications. \\
\hline Save Image & Completed, may need modifications. \\
\hline VCS Triples & Completed. \\
\hline
\end{tabular}

VCS version 2.7 is currently released to PCMDI users and to the public.

\section{Web Development and Software Documentation}

Documentation is an important means to inform users of PCMDI's software products. Documentation also explains the problem the software addresses, describes the purpose and requirements of the software, and shows how to use the software by providing relevant examples.

All of PCMDI's software products described in this report will be documented to high standards of quality and will be accessible via the World Wide Web. Currently, documentation for five of PCMDI's software products (DDI, DRS, EzGET, LATS, and VCS) may be viewed at Web address http://www-pcmdi.llnl.gov/software/

Also, on our Web site, PCMDI software users can submit bug and enhancement requests via the "PCMDI Software Bugs Form" and the "PCMDI Software Enhancements Request Form", respectively.

Software documentation will be provided in several formats, including compressed HTML, Adobe Acrobat PDF, and compressed book-form Postscript with pagination, table of contents, and index.

\section{Multiple Platforms}

All software products listed in the PCMDI Software System are able to run on the following platforms:

\begin{tabular}{|l|l|}
\hline \multicolumn{1}{|c|}{ Platforms } & \multicolumn{1}{c|}{ Operating Systems } \\
\hline Cray C90 and J90 & UNICOS 8.0 \\
\hline DEC(Digital Equipment Corporation) & OSF 3.2 \\
\hline HP (Hewlett Packard) & HP-UX 9.0.5 or higher \\
\hline IBM(International Business Machines) & AIX 3.5 or higher \\
\hline PC (Personal Computer) & Linux 3.0.3 or higher \\
\hline SGI (Silicon Graphics, Inc.) & IRIX 5.2, 5.3, or 6.1 \\
\hline SUN Microsystems, Inc. & SunOS 4.1.3 or Solaris 2.4 or higher \\
\hline
\end{tabular}


Note: PCMDI will work towards porting our software products to Windows NT. This will be done either by rewriting the code to work in the Windows NT environment, or by porting the UNIX/X11R6/Motif/C/FORTRAN code using NutCracker NT or OpenNT.

\section{Software Collaborations}

In July of 1995, PCMDI software team members met with Dave Williamson and Jim Hack of the National Center for Atmospheric Research (NCAR), at which time the Visualization and Computation System (VCS) was demonstrated. As it was clear that PCMDI and NCAR would greatly benefit from collaboration, Dean Williams subsequently drafted a PCMDI-NCAR collaboration agreement. PCMDI's part of the agreement was to provide NCAR with VCS, and to design and develop a calculator for climate analysis (now designated as CDAT). NCAR's part of the agreement was to provide PCMDI with climate diagnostic routines.

In May of 1997, PCMDI software team members met with Dr. Bob Malone, the director of the Advanced Computing Laboratory (ACL) at Los Alamos National Laboratory. After demonstration and discussion VCS and CDAT, PCMDI and ACL also entered into a software collaboration agreement. PCMDI will provide ACL with software products (i.e., PCMDI's Software System) and ACL will provide PCMDI with oceanic numeric functions.

\section{Code Repository}

Since PCMDI has a large amount of developed code, it is imperative that some type of code history be implemented. To maintain current and future code, the PCMDI staff has elected to use the Concurrent Version System (CVS). CVS will provide network-transparent source code control for PCMDI's software system, and will assist the software development team by providing the following features.

- CVS will maintain a history of all PCMDI software changes made to each directory tree. Using this history, CVS can recreate past states of the tree, or show a developer when, why, and by whom a given change was made. By supporting branches, CVS will help manage long-term changes and bug-fix releases.

- CVS will provide reliable access to PCMDI's software directory trees from remote hosts, using internet protocols. The PCMDI software team member, working either from home or at a remote site, can perform all the same operations as are available locally. Access can be authenticated using the Kerberos network security system.

- Most importantly, CVS supports parallel development, allowing more than one developer to work on the same sources at the same time.

Cyclic Software provides commercial support and development expertise for CVS. They have been contacted, and approval to purchase and setup CVS for our entire software system is underway. Dean Williams, Bob Drach, and Susan Marlais will be in charge of setting up this system. 
Each person on the PCMDI software team will be expected to follow the following CVS protocols when developing or maintaining the PCMDI Software System. (The version control is described below by Cyclic Software.)

- Each developer uses the command cvs checkout to create their own copy of the source tree from the CVS repository. The command can operate on a directory tree, on a single file, or on a module; a module groups several files or directories into one entity, which can be operated on as a unit. One defines modules by editing the 'modules' file.

- The developer modifies, compiles, and tests the code in their copy of the source tree (called a working directory) with whatever editors and tools they choose -- Emacs, make, etags, etc. Users will use commands cvs add and cvs remove to add and remove files.

- When the changes are complete, the developer uses the command cvs commit to merge changes back into the repository. This makes her changes available to other developers.

- At any point, the developer may use the command cvs update to merge changes committed by others into her working directory. If there are uncommitted changes to files in their working directory, CVS prints a message and attempts to merge the changes from the repository with their changes in the working directory. If the merge fails, CVS indicates a conflict, which the developer resolves manually with a text editor.

- The developer can show the differences between two revisions with the command cvs diff; show the log of changes to a particular file with cvs log; show the history of each line of a file with cvs annotate; and show who has used cvs checkout, cvs tag, and several other CVS commands, by using the cvs history command.

- CVS supports watches, allowing developers to request notification when someone else begins editing a file, or to obtain a list of developers currently working on a file.

- The user can record the state of the repository at a particular point with the cvs tag command, and can then use that tag as an argument to most CVS commands, for example to retrieve the files as of the tagged point.

- The developer can create a new development branch with the command cvs tag -b, and manipulate branches with cvs update -r and cvs checkout -r. Subsequent operations in that working directory apply to that branch. To return to the main branch, the developer can use cvs update - $\mathbf{A}$. The cvs update -j command merges changes made on another branch into the working directory.

- The existence or nonexistence of a file is itself version controlled, so that files can exist on some, but not all, branches and users can reproduce the state of the files at any given point in time. 
- The developer can mark a file as binary, which prohibits merging and line terminator conversions, using the command cvs admin -kb.

- Wrappers allow the developer to run files through a filter on their way in or out of CVS; for example, developers can instruct CVS to apply the indent command to source files before committing the changes.

The CVS client and server run on most UNIX platforms. (PCMDI will be developing and maintaining code on SUN and SGI machines.) The CVS client also runs on Windows NT, a desirable feature since we may wish to port the PCMDI Software System over to Windows NT in the future.

\section{Summary of the PCMDI Software System}

The principal mission of the Program for Climate Model Diagnosis and Intercomparison (PCMDI) is to develop improved and seamlessly interconnected methods for the diagnosis, validation and intercomparison of global climate models. The need for such standards has become increasingly apparent as more complex climate models are developed, while the disagreements among models, and between models and observations, remains significant and poorly documented. The nature and causes of these disagreements must be better understood before these models can be confidently used for climate sensitivity and predictability studies in support of global change research.

The PCMDI Software System was designed to aid climate scientists in the study of global climate models. Its concept is simple and flexible enough to interchange its parts and expand in the future. The primary software system comprises of three parts: CDAT manipulates data and provide climate scientists with diagnostic, statistical, and regridding routines; CDMS automatically locates and extracts metadata (i.e., variables, dimensions, grids, etc.) from PCMDI's collection of model runs and analysis files; and VCS, a graphics software package to display, animate, and manipulate scientific data.

Each one of these software products is independent and can run as a standalone process or can run together as part of a single process. The three systems share common scripting commands implemented by Python, an interpreted, object-oriented language, and are available for use in C or FORTRAN applications via an API. In the figure below, the central box "Script" represents Python, the mechanism that connects all PCMDI software. 


\section{PCMDI Software System}

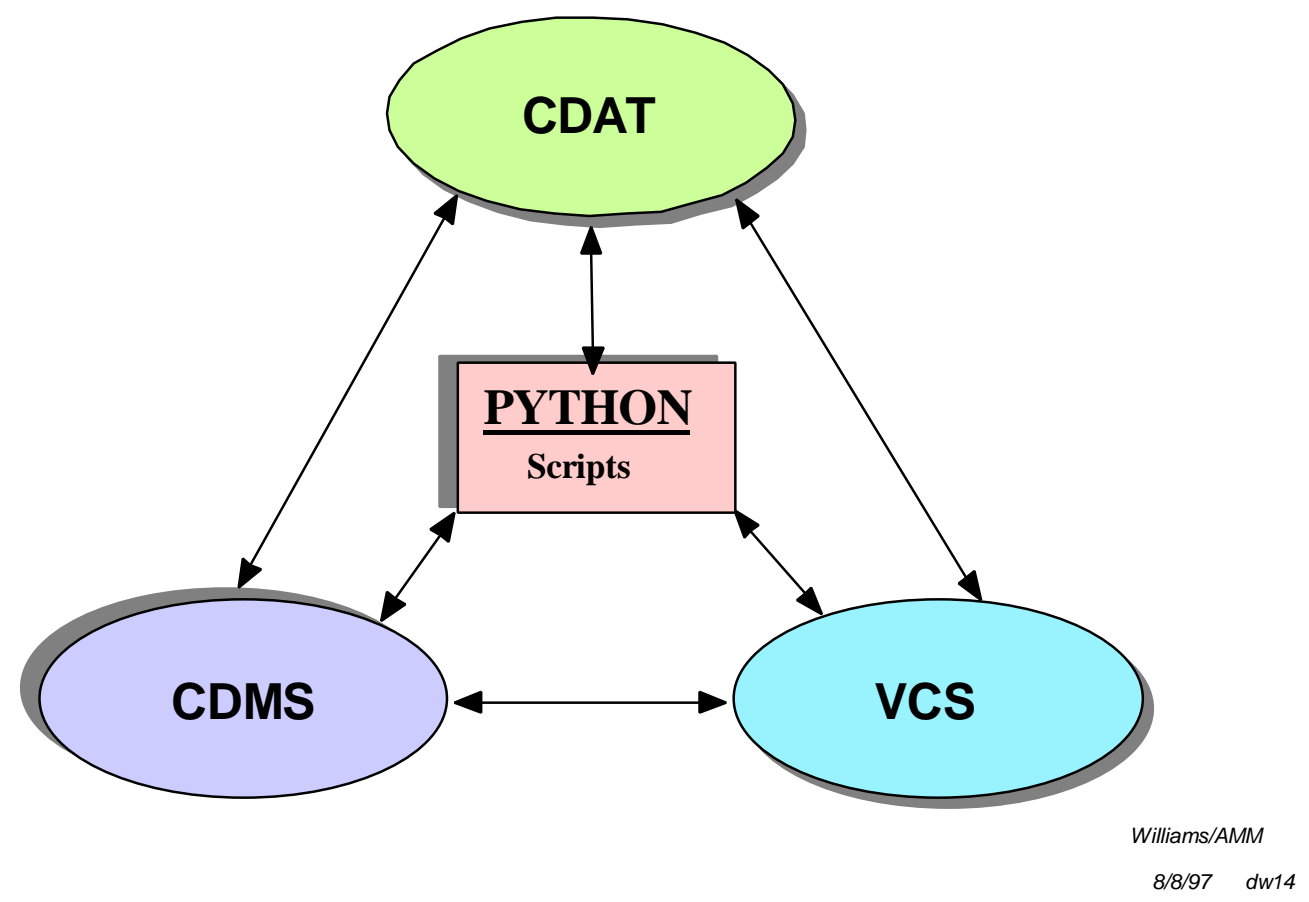

Figure 13. Conceptual view of PCMDI's Software System.

When running CDAT as a standalone process, a command line user interface will appear along with a CDAT output window. The "CDAT $>$ " prompt will wait for the user to input a command CDAT command. Through this interface, data are manipulated, and the other two software systems can be accessed via a Python script command. Therefore, a likely scenario in a CDAT session would be to search the directory for data, manipulate the data, and then plot the data via VCS. To help users move quickly through the data, some of the VCS GUI widgets are included in (e.g., "Animation Panel", "Colormap Editor", etc.). CDAT also contains an on-line help menu for quick command lookup.

CDMS is similar to CDAT in its command line user interface, the only exception being the prompt "CDMS $>$ " instead of "CDAT $>$ ". CDMS also can be initiated to run in an Xterm window. When operating in this mode, the user has no access to CDAT or CDMS, but still can run scripts that are designated to be done by CDMS. In that event, the prompt at the Xterm window then changes to "PSQL>" which stands for PCMDI Structured Query Language.

VCS has the ability to run in batch mode or from an elaborate graphical user interface (GUI). Because VCS was developed first, and in order to accommodate the many current VCS users, CDAT and CDMS are designed to be accessed from within the VCS GUI. Thus, the user will be able to choose whether to access data files and variables via the currently implemented directory, or though CDMS, using PSQL calls. Here, data manipulation will be done with CDAT via a point-and-click environment or through the command line user interface. 
Taken together, PCMDI software tools are designed to provide climate scientists with the best possible means to analyze their data. These software products allow manipulation of data to perform needed calculations, display of results annotation of various data file formats and access of multi-dimensional arrays.

\section{PCMDI Software Tools Overview}

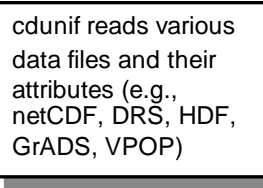

GTAD, $V P O P)$

Annotation
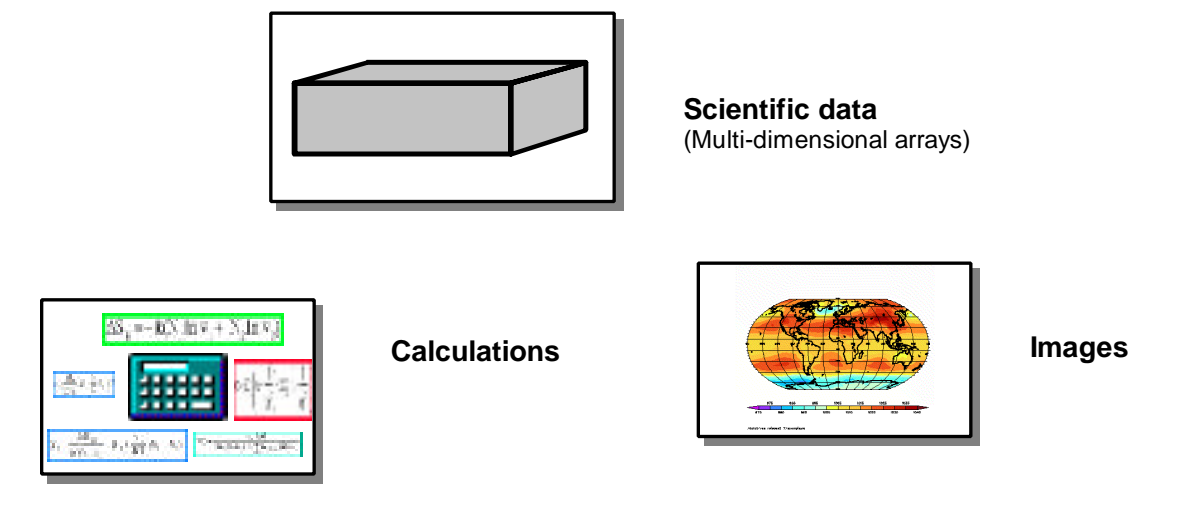

\begin{tabular}{|c|c|c|}
\hline$\underline{\mathbf{X}}$ & $\underline{\mathbf{Y}}$ & $\underline{\mathbf{Z}}$ \\
4.1586 & 25.697 & .78341 \\
6.9214 & 38.451 & .77549 \\
2.9182 & 67.904 & .87401 \\
4.0913 & 58.743 & .90428 \\
\hline
\end{tabular}

Scientific data

(Multi-dimensional arrays)

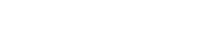

Figure 14. Conceptual view of PCMDI's Software System.

For further information on PCMDI and the PCMDI Software System visit our Web site at URL http:/www-pcmdi.llnl.gov/ 


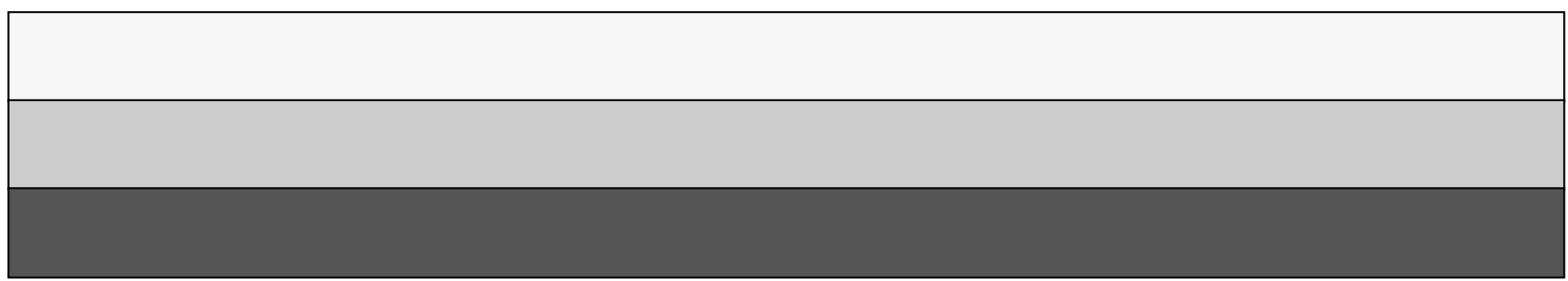

